\title{
Continental pollution in the Western Mediterranean basin: large variability of the aerosol single scattering albedo and influence on the direct shortwave radiative effect
}

\author{
Claudia Di Biagio ${ }^{1}$, Paola Formenti ${ }^{1}$, Lionel Doppler ${ }^{2}$, Cécile Gaimoz ${ }^{1}$, Noel Grand ${ }^{1}$, Gerard Ancellet $^{3}$, \\ Jean-Luc Attié ${ }^{4,5}$, Silvia Bucci ${ }^{6,7}$, Philippe Dubuisson ${ }^{8}$, Federico Fierli ${ }^{6}$, Marc Mallet $^{5}$, and François Ravetta ${ }^{3}$ \\ ${ }^{1}$ LISA, UMR CNRS 7583, Université Paris Est Créteil et Université Paris Diderot, Institut Pierre Simon Laplace, \\ Créteil, France \\ ${ }^{2}$ Deutscher Wetterdienst, Meteorological Observatory Lindenberg, Lindenberg (Tauche), Germany \\ ${ }^{3}$ Sorbonne Universités, UPMC Univ. Paris 06, Université Versailles St-Quentin, CNRS/INSU, LATMOS-IPSL, Paris, France \\ ${ }^{4}$ Laboratoire d'Aérologie, University of Toulouse, UMR 5560 CNRS, Toulouse, France \\ ${ }^{5}$ CNRM UMR 3589, Météo-France/CNRS, Toulouse, France \\ ${ }^{6}$ Institute for Atmospheric Sciences and Climate of the National Research Council (ISAC-CNR), Rome, 00133, Italy \\ ${ }^{7}$ Sc. Dept. of Physics, Ferrara University, Ferrara, 44121, Italy \\ ${ }^{8}$ Laboratoire d'Optique Atmosphérique, Université Lille, Villeneuve d'Ascq, 59655 CEDEX, France
}

Correspondence to: Claudia Di Biagio (claudia.dibiagio@lisa.u-pec.fr) and Paola Formenti (paola.formenti@lisa.u-pec.fr)

Received: 16 January 2016 - Published in Atmos. Chem. Phys. Discuss.: 11 April 2016

Revised: 1 July 2016 - Accepted: 8 July 2016 - Published: 25 August 2016

\begin{abstract}
Pollution aerosols strongly influence the composition of the Western Mediterranean basin, but at present little is known on their optical properties. We report in this study in situ observations of the single scattering albedo $(\omega)$ of pollution aerosol plumes measured over the Western Mediterranean basin during the TRAQA (TRansport and Air QuAlity) airborne campaign in summer 2012. Cases of pollution export from different source regions around the basin and at different altitudes between $\sim 160$ and $3500 \mathrm{~m}$ above sea level were sampled during the flights. Data from this study show a large variability of $\omega$, with values between 0.84 0.98 at $370 \mathrm{~nm}$ and $0.70-0.99$ at $950 \mathrm{~nm}$. The single scattering albedo generally decreases with the wavelength, with some exception associated to the mixing of pollution with sea spray or dust particles over the sea surface. The lowest values of $\omega(0.84-0.70$ between 370 and $950 \mathrm{~nm})$ are measured in correspondence of a fresh plume possibly linked to ship emissions over the basin. The range of variability of $\omega$ observed in this study seems to be independent of the source region around the basin, as well as of the altitude and aging time of the plumes. The observed variability of $\omega$ reflects in a large variability for the complex refractive index of pollution aerosols, which is estimated to span in the large range 1.41-
\end{abstract}

1.77 and $0.002-0.097$ for the real and the imaginary parts, respectively, between 370 and $950 \mathrm{~nm}$.

Radiative calculations in clear-sky conditions were performed with the GAME radiative transfer model to test the sensitivity of the aerosol shortwave Direct Radiative Effect (DRE) to the variability of $\omega$ as observed in this study. Results from the calculations suggest up to a 50 and $30 \%$ change of the forcing efficiency (FE), i.e. the DRE per unit of optical depth, at the surface $\left(-160 /-235 \mathrm{~W} \mathrm{~m}^{-2} \tau^{-1}\right.$ at $60^{\circ}$ solar zenith angle) and at the Top-Of-Atmosphere $\left(-137 /-92 \mathrm{~W} \mathrm{~m}^{-2} \tau^{-1}\right)$ for $\omega$ varying between its maximum and minimum value. This induces a change of up to an order of magnitude $\left(+23 /+143 \mathrm{~W} \mathrm{~m}^{-2} \tau^{-1}\right)$ for the radiative effect within the atmosphere.

\section{Introduction}

Atmospheric aerosols play a crucial role on climate by affecting the radiative transfer of atmospheric radiation and by modifying cloud properties and lifetime (Boucher et al., 2013). The capability of atmospheric aerosols to interact 
through processes of scattering and absorption with the atmospheric radiation, so to exert a direct radiative effect (DRE), depends on their spectral optical properties (extinction efficiency, $k_{\text {ext }}$, single scattering albedo, $\omega$, and asymmetry factor, $g$ ). In particular the single scattering albedo has been demonstrated to be a key parameter in modulating the surface, Top-of-Atmosphere (TOA), and atmospheric aerosol DRE (e.g., Ramana and Ramanathan, 2006; Di Biagio et al., 2010; Loeb and Su, 2010). Aerosol optical properties can largely vary depending on the particles composition, size distribution, and shape, which are function of the aerosol source, type, and processing occurring during atmospheric lifetime. At present, the capability of climate models in reproducing all the possible heterogeneity in aerosol optical properties represents the main source of uncertainty in evaluating their DRE on climate (McComiskey et al., 2008; Stier et al., 2013). In this sense, intensive studies providing the characterization of the aerosol optical properties and their local and regional variability are of great importance in order to reduce these uncertainties.

This is particularly the case of the Western Mediterranean basin. Indeed, the Mediterranean is a very complex region, characterized by the presence of air masses carrying aerosols of different origins and types (Gkikas et al., 2012). On its northern bound, it is limited by Europe, with a consequent frequent export of anthropogenic pollution from the continent towards the basin (Lelieveld et al., 2002; Pace et al., 2006). In particular, the Western part of the Mediterranean basin, surrounded by large coastal megacities, commercial harbours, and under the direct influence of some of the most industrialized areas of the continent (such as the Po Valley in Northern Italy or the Fos/Berre area in Southern France), is strongly affected by continental pollution outflows (Pérez et al., 2008; Pey et al., 2010; Di Biagio et al., 2015). The build-up of high pollution levels over the Western basin is particularly favoured during summer when the strong insolation enhances photochemical reactions and the stable meteorological conditions promote the stagnation of pollutants (Millan et al., 2000; Mallet et al., 2005).

In spite of this, the characterization of the optical properties of anthropogenic aerosols in this part of the basin remains only limited to coastal and inland regions (Mallet et al., 2003, 2011, 2013; Lyamani et al., 2006; Estelles et al., 2007; Saha et al., 2008; Esteve et al., 2012; Piazzola et al., 2012; Pandolfi et al., 2011, 2014), or remote islands actually far from the strong influence of continental outflows (Lyamani et al., 2015). Moreover, the majority of these studies uses remote-sensing measurements and analyse aerosol properties integrated over the entire atmospheric column, without information on their vertical variability. Thus, at present, we miss a detailed characterization of the optical properties of the pollution aerosol over the entire region, in particular over the remote sea, and its vertical distribution.

To fill this gap, the international ChArMEx (Chemistry-Aerosol Mediterranean Experiment; http://charmex.lsce.ipsl.fr) research program has supported in recent years two airborne campaigns over the Western Mediterranean basin: TRAQA (Transport and Air QuAlity) in 2012 and SAFMED (Secondary Aerosol Formation in the MEDiterranean) in 2013.

In a recent paper, Di Biagio et al. (2015) have presented in situ measurements of the aerosol vertical profiles acquired over the remote sea during these campaigns. Observations from TRAQA and SAFMED have shown that in the Western basin pollution plumes extend as far as hundreds of kilometres from the coastline and reach up to $\sim 4000 \mathrm{~m}$, presenting a complex stratified structure, and pollution plumes show a large heterogeneity in terms of composition, origin, and lifetime.

Following these observations, we may ask the following: does the heterogeneity in pollution plume composition, origin, and lifetime as observed in Di Biagio et al. (2015) induce heterogeneity on the optical properties (in particular the single scattering albedo) of pollution aerosols in this part of the basin? And, if observed, does this heterogeneity on the optical properties influence the aerosol DRE? Is it necessary to take it into account to better evaluate the aerosol radiative impact in the Western Mediterranean?

With the aim of answering these questions, in this paper we analyse data of the optical properties (spectral scattering and absorption coefficients, single scattering albedo) and size distributions of pollution aerosols measured over the Western Mediterranean basin during TRAQA. SAFMED observations have been excluded here given that only limited data on the aerosol optical properties were available from this campaign. The objective of the paper is twofold: to provide a new data set of aerosol single scattering albedo values which can be representative of the polluted aerosols over the Western basin, and investigate the sensitivity of the aerosol direct DRE to the variability of this parameter.

\section{Overview of flights during the TRAQA campaign}

The TRAQA campaign took place in the period 20 June13 July 2012. Instruments were installed on board the SAFIRE (Service des Avions Français Instruments pour la Recherche en Environnement, http://www.safire.fr/) tropospheric aircraft ATR-42, based in Toulouse $\left(43^{\circ} 36^{\prime} \mathrm{N}\right.$, $1^{\circ} 26^{\prime} \mathrm{E}$, France). A total of 17 flights, most often two flights per day, with intermediate stops in different airports in southern France and Corsica, were performed (flight numbers V16 to V32). The majority of flights were over the sea, with some exceptions investigating inland areas in southern France. The flight altitude for the ATR-42 ranged between a minimum of $\sim 60 \mathrm{~m}$ to a maximum of $\sim 5000 \mathrm{~m}$ above sea level (a.s.l.), and the maximum flight time was $4 \mathrm{~h}$. The general flight strategy consisted of legs at constant altitude to sound the vertical structure by lidar observations, vertical ascents and/or descents to describe the vertical atmospheric column and iden- 


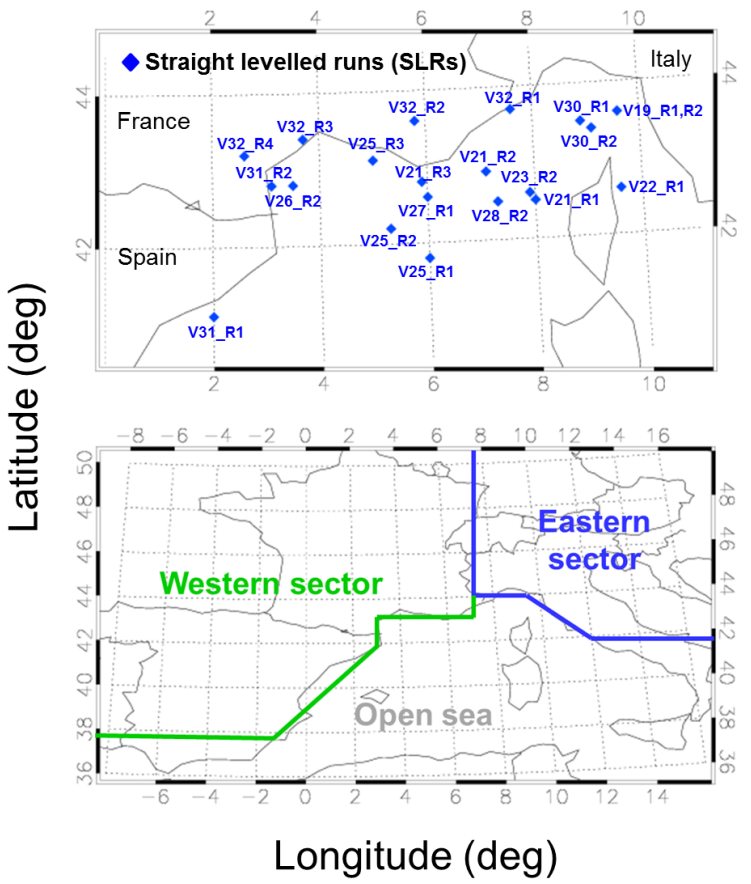

Figure 1. (upper panel) Geographical position of the different straight levelled runs (SLRs) performed during the TRAQA campaign and analysed in this paper. The label for each point in the figure identifies the flight number and the corresponding SLR: for example V22_R1 indicates the coordinates of the first SLR of flight V22. (lower panel) Definition of three different source areas for the various SLRs (see Sect. 3.4 for more details). The Western sector includes trajectories coming from the Atlantic Ocean and travelling over France or northern Spain before reaching the Western basin; the Eastern sector includes air mass trajectories from continental Europe that have travelled over northern Italy-Po Valley before entering the basin; and the Open sea sector consists of trajectories which have experienced at least 2 days of subsidence over the sea in the Western basin.

tify the main aerosol plumes, followed by straight levelled runs (SLRs) within the detected aerosol layers. In the present study we will exclusively consider measurements acquired during SLRs, since only during these phases the whole set of aerosol optical properties (scattering and absorption coefficients) were measured. A total of 21 SLRs were performed over the sea surface or inland close to the coastline and will be considered in this study. Figure 1 and Table 1 summarize the geographical location, date, time, and altitude of these 21 SLRs. As indicated in Table 1 each SLR was about 1520 min long. At the cruise speed of the ATR $\left(93 \mathrm{~m} \mathrm{~s}^{-1}\right)$, this integration time corresponds to about $100 \mathrm{~km}$.

\section{Measurements and methods}

\subsection{Aircraft observations}

Aerosol sampling on the ATR-42 was performed using the AVIRAD system. AVIRAD is an iso-axial and iso-kinetic inlet which samples air at a volumetric flow of $\sim 350 \mathrm{~L} \mathrm{~min}^{-1}$. The $50 \%$ passing efficiency of the inlet is $12 \mu \mathrm{m}$ diameter. Various lines depart from AVIRAD to connect to different instruments for the measurement of the aerosol physicochemical and optical properties. Additionally, several sensors for the measurements of the atmospheric composition were installed on the ATR-42 aircraft as basic equipment. A brief description of the different in situ measurements considered in this study from the AVIRAD system and the ATR42 equipment and their data analysis is reported in the following.

The aerosol scattering coefficient $\left(\sigma_{\mathrm{s}}\right)$ at 450,550 , and $700 \mathrm{~nm}$ was measured by a three-wavelength integrating nephelometer (TSI Inc., model 3563, $6 \mathrm{~s}$ resolution). The nephelometer was calibrated prior to the campaign by using air and $\mathrm{CO}_{2}$ as reference gases. Nephelometer measurements were corrected for angular truncation and Lambertian non-idealities by applying the formula by Anderson and Ogren (1998), appropriated to submicron aerosols which we expected in the pollution plumes sampled during the campaign. The measurement uncertainty on $\sigma_{\mathrm{s}}$, calculated taking into account for the photon counting, gas calibration, and angular corrections uncertainties, was estimated to be lower than $10 \%$ at the three wavelengths. Averages of the scattering coefficient were calculated over the different SLRs. The uncertainty on the SLR average values was estimated as the combination of the measurement uncertainty and the standard deviation along each individual run. For each SLR, the particle scattering Ångström exponent (SAE) was calculated as the power law fit of the measured scattering coefficients versus wavelength to extrapolate the scattering coefficient at other wavelengths than those of operation.

The nephelometer measured the scattering coefficient in dry air conditions. This is due to the heating of the airflow while entering the aircraft cabin and the temperature increase in the sensing volume of the instrument due to illumination. The relative humidity measured during the flights inside the nephelometer cavity was $<25 \%$ in more than $90 \%$ of cases, with values up to $\sim 40 \%$ occasionally observed $<200 \mathrm{~m}$ over the sea surface.

The aerosol absorption coefficient $\left(\sigma_{\text {abs }}\right)$ at 370,470 , $520,590,660,880$, and $950 \mathrm{~nm}$ was measured by a sevenwavelength aethalometer (Magee Sci., model AE31, 2 min resolution). The principle of operation of the aethalometer consists in measuring the attenuation of light through an aerosol-laden filter compared to that of another portion of the filter which is unexposed to the air flow and is used as a reference (Weingartner et al., 2003). To yield the aerosol absorption coefficient, the spectral attenuation $\sigma_{\mathrm{ATT}}(\lambda)$ mea- 
Table 1. Summary of information on the SLRs analysed in this study. The SLR location (within the boundary layer or in the free troposphere) was determined based on the boundary layer top height estimated for the closest vertical sounding performed during each flight (see Sect. 3.3). The sector of origin for sampled air masses was determined based on FLEXPART back-trajectories (see Fig. 1 and Sect. 3.4 for further details).

\begin{tabular}{llllrll}
\hline Flight number & SLR_ID & Date & Time start-stop & Altitude (m) & Location & Sector of origin \\
\hline V19 & V19_R1 & 26 June 2012 & $11: 23-11: 38$ & 322 & Within the boundary layer & Eastern \\
V19 & V19_R2 & 26 June 2012 & $11: 44-11: 59$ & 897 & Within the boundary layer & Eastern \\
V21 & V21_R1 & 27 June 2012 & $10: 54-11: 12$ & 312 & Within the boundary layer & Eastern \\
V21 & V21_R2 & 27June 2012 & $11: 48-12: 04$ & 629 & Within the boundary layer & Eastern \\
V21 & V21_R3 & 27 June 2012 & $12: 05-12: 19$ & 311 & Within the boundary layer & Western \\
V22 & V22_R1 & 29 June 2012 & $07: 42-08: 01$ & 478 & Within the boundary layer & Eastern \\
V23 & V23_R2 & 29 June 2012 & $12: 05-12: 20$ & 319 & Within the boundary layer & Open sea \\
V25 & V25_R1 & 4 July 2012 & $09: 08-09: 24$ & 639 & Within the boundary layer & Western \\
V25 & V25_R2 & 4 July 2012 & $09: 32-09: 48$ & 2015 & Free troposphere & Western \\
V25 & V25_R3 & 4 July 2012 & $09: 50-10: 08$ & 2538 & Free troposphere & Western \\
V26 & V26_R2 & 4 July 2012 & $17: 08-17: 25$ & 1877 & Free troposphere & Western \\
V27 & V27_R1 & 6 July 2012 & $09: 28-09: 47$ & 164 & Within the boundary layer & Open sea \\
V28 & V28_R2 & 6 July 2012 & $15: 58-16: 13$ & 927 & Within the boundary layer & Open sea \\
V30 & V30_R1 & 7 July 2012 & $14: 09-14: 28$ & 3498 & Free troposphere & Western \\
V30 & V30_R2 & 7 July 2012 & $14: 51-15: 07$ & 549 & Within the boundary layer & Open sea \\
V31 & V31_R1 & 10 July 2012 & $15: 44-16: 20$ & 322 & Within the boundary layer & Western \\
V31 & V31_R2 & 10 July 2012 & $16: 31-16: 59$ & 954 & Within the boundary layer & Western \\
V32 & V32_R1 & 11 July 2012 & $12: 52-13: 13$ & 250 & Within the boundary layer & Western \\
V32 & V32_R2 & 11 July 2012 & $13: 22-13: 48$ & 788 & Within the boundary layer & Western \\
V32 & V32_R3 & 11 July 2012 & $14: 02-14: 12$ & 336 & Within the boundary layer & Western \\
V32 & V32_R4 & 11 July 2012 & $14: 18-14: 35$ & 802 & Within the boundary layer & Western \\
\hline
\end{tabular}

sured by the aethalometer was corrected following the procedure described by Collaud Coen et al. (2010):

$\sigma_{\mathrm{abs}}(\lambda)=\frac{\sigma_{\mathrm{ATT}}(\lambda)-\alpha(\lambda) \overline{\sigma_{\mathrm{s}}(\lambda)}}{C_{\mathrm{ref}} R(\lambda)}$

The different terms in Eq. (1) are the following: (i) $\alpha(\lambda) \overline{\sigma_{\mathrm{s}}(\lambda)}$ or "scattering correction". In this work $\alpha(\lambda)$ was calculated with the formula by Arnott et al. (2005) and varied between 0.02 and 0.07 , while $\overline{\sigma_{\mathrm{s}}(\lambda)}$ was the average of the scattering coefficient along the considered SLR extrapolated at the aethalometer wavelengths; (ii) $C_{\text {ref }}$ or "multiple scattering correction". $C_{\text {ref }}$ was set to $2.14 \pm 0.21$ (wavelengthindependent) following Weingartner et al. (2003); (iii) $R(\lambda)$ or "shadowing effect correction". $R(\lambda)$ depends on the charge and absorptivity properties of the sampled aerosol and can be calculated as a function of the particle single scattering albedo $(\omega)$. In this study, because of the absence of an independent determination of $\omega$, we used an estimated "firstguess" single scattering albedo $\left(\omega^{*}\right)$ to calculate $R$. This was determined as the ratio of the measured scattering $\left(\sigma_{\mathrm{s}}\right)$ to extinction $\left(\sigma_{\mathrm{s}}+\sigma_{\mathrm{abs}}^{*}\right)$ coefficients, with $\sigma_{\mathrm{abs}}^{*}$ corrected for the scattering and the multiple scattering corrections, but not for the shadowing effect. The obtained $R(\lambda)$ varied between 0.75 and 1 for $\omega^{*}$ between $0.75-0.99$ at $370 \mathrm{~nm}$ and 0.70 0.99 at $950 \mathrm{~nm}$. The whole uncertainty on the absorption coefficient was estimated with the propagation error formula taking into account for the different factors in Eq. (1) and varied between $11-36 \%$ at $370 \mathrm{~nm}$ and $12-70 \%$ at $950 \mathrm{~nm}$.

It has to be noticed that an enhanced absorption at single wavelengths was observed in several cases for the aethalometer. This was possibly due to the absorption on the exposed filter of gases or volatile compounds absorbing at some of the instrument operating wavelengths (Weingartner et al., 2003). These anomalous points were accurately selected and screened from the data set. As a result of this screening, data in correspondence of only $60 \%$ of the considered SLRs were available for aerosols analyses.

The measured aerosol scattering and absorption coefficients were used to calculate the particle spectral single scattering albedo between 370 and $950 \mathrm{~nm}$ as

$\omega(\lambda)=\frac{\sigma_{\mathrm{s}}(\lambda)}{\sigma_{\mathrm{s}}(\lambda)+\sigma_{\mathrm{abs}}(\lambda)}$.

The uncertainty on $\omega$ was calculated with the propagation error formula and varied between 0.02 and 0.04 at all wavelengths.

Additionally, for each SLR for which aethalometer data were available, the particle absorption Ångström exponent (AAE) was calculated as the power law fit of the measured absorption coefficients versus wavelength.

The aerosol number size distribution $\left(\mathrm{d} N / \mathrm{d} \log D_{\mathrm{g}}\right)$ was measured by two different optical particle spectrometers: the passive cavity aerosol spectrometer probe (PCASP, model 
$100-\mathrm{X}, 1 \mathrm{~s}$ resolution, 31 size classes between 0.1 and $3.0 \mu \mathrm{m}$ diameter, operating wavelength $632.8 \mathrm{~nm}$ ), and the optical particle spectrometer GRIMM (GRIMM Inc., model 1.129, $6 \mathrm{~s}$ resolution, 32 size classes between 0.3 and $32 \mu \mathrm{m}$ diameter, operating wavelength $655 \mathrm{~nm}$ ). For both the PCASP and the GRIMM, the measured sphere-equivalent optical diameter was converted in a sphere-equivalent geometrical diameter $\left(D_{\mathrm{g}}\right)$ by taking into account the complex refractive index of the sampled aerosol (Liu and Daum, 2000). Differently from Di Biagio et al. (2015), where the complex refractive index used to correct the size was fixed based on literature values $(n=1.52 / 1.70, k=0.01$ for pollution aerosols in the Mediterranean), here the complex refractive index to correct the size was iteratively adjusted based on optical closure calculations. Full details of the procedure are provided in Sect. 3.2. After optical closure and refractive index correction the $D_{\mathrm{g}}$ range varied between $0.10-4.24$ and $0.10-$ $4.84 \mu \mathrm{m}$ for the PCASP and 0.26-58.75 and 0.30-73.60 $\mu \mathrm{m}$ for the GRIMM as a function of the assumed aerosol refractive index. The uncertainty on $D_{\mathrm{g}}$ is between 1 and $25 \%$. For comparison, the $D_{\mathrm{g}}$ values obtained in Di Biagio et al. (2015) were $0.10-4.47$ and $0.28-65.80 \mu \mathrm{m}$ for the PCASP and the GRIMM, respectively. The smallest and the largest size bins of both instruments, for which the minimum and maximum edges respectively are not defined, were excluded from the data sets, thus reducing the PCASP and GRIMM $D_{\mathrm{g}}$ ranges to $0.10-3.94$ and $0.11-4.53 \mu \mathrm{m}$ for the PCASP and $0.28-$ 50.01 and 0.34-63.03 $\mu \mathrm{m}$ for the GRIMM.

Corrected data from the PCASP and the GRIMM were then merged to obtain the aerosol size distribution over a larger size range. The two instruments superimpose in a large interval covering the diameter range $\sim 0.30-4.0 \mu \mathrm{m}$. In this interval the PCASP and the GRIMM showed a good agreement below 0.4 and above $1.0 \mu$ m (less than $\sim 10 \%$ difference), while significant differences were observed in the $0.4-$ $1.0 \mu \mathrm{m}$ range where the PCASP underestimates the GRIMM measurements by more than $\sim 50 \%$. This difference is of great relevance in terms of optical properties because particles in the $0.4-1.0 \mu \mathrm{m}$ size interval are very efficient for interaction with shortwave radiation. With the aim of understanding which of the two instruments measures correctly in the $0.4-1.0 \mu \mathrm{m}$ range we performed an optical test, which consisted in calculating with Mie theory the scattering coefficient at 450, 550, and $700 \mathrm{~nm}$ based on the PCASP and GRIMM size data, and then in comparing it with simultaneous nephelometer measurements. Optical calculations were performed by fixing the complex refractive index at $1.6-0.01 i$, so at the mean of the range of values reported in the literature for pollution aerosols (Ebert et al., 2002, 2004; Mallet et al., 2003, 2011; Müller et al., 2002; Raut and Chazette, 2008). SLRs characterized by a low variability in terms of scattering coefficient and particle concentration were selected. The results of the optical test indicate that in the $0.4-1.0 \mu \mathrm{m}$ range the size distribution of the GRIMM is more accurate since it permits to most closely re- produce nephelometer observations $(<5 \%$ mean difference between calculations and observations at the three wavelengths, compared to differences up to $15-21 \%$ if PCASP data are used in the $0.4-1.0 \mu \mathrm{m}$ size range). Thus, a combined PCASP-GRIMM number size distribution $\mathrm{d} N / \mathrm{d} \log D_{\mathrm{g}}$ in the $\sim 0.10$ to $50.01-63.03 \mu \mathrm{m}$ diameter range was estimated by considering PCASP data up to $0.30 \mu \mathrm{m}$ and GRIMM data above. The volume size distribution was also computed as $\mathrm{d} V / \mathrm{d} \log D_{\mathrm{g}}=\pi / 6 D_{\mathrm{g}}^{3} \mathrm{~d} N / \mathrm{d} \log D_{\mathrm{g}}$. Averages of the number and volume size distributions over each SLRs were calculated.

Nonetheless, due to a technical problem, GRIMM data were only available below $\sim 350 \mathrm{~m}(\sim 970 \mathrm{hPa})$.

The total particle number concentrations in the ultrafine mode $\left(4 \mathrm{~nm}-0.1 \mu \mathrm{m} ; \mathrm{d} N_{\mathrm{UFP}}\right.$, i.e. formerly defined as Aitken mode in Di Biagio et al., 2015) and accumulation mode (0.1$1.0 \mu \mathrm{m} ; \mathrm{d} N_{\text {Acc }}$ ) were calculated by combining condensation particle counter measurements of particle concentration in the 0.004-3 $\mu \mathrm{m}$ range (CPC, TSI Inc., model 3775, 5-s resolution) and size distribution data. Due to the fact that above $350 \mathrm{~m}$ the GRIMM was not available, only PCASP data were used in the calculations of $\mathrm{d} N_{\text {UFP }}$ and $\mathrm{d} N_{\text {Acc }}$ over the whole altitude range. $\mathrm{d} N$ UFP was estimated as the difference between CPC concentration and the integral of PCASP data between 0.1 and $3.0 \mu \mathrm{m}$, while $\mathrm{d} N_{\text {Acc }}$ was obtained by integrating the PCASP number concentrations in the $0.1-1.0 \mu \mathrm{m}$ interval. The underestimation of the PCASP number concentration between 0.4 and $1.0 \mu \mathrm{m}$, as discussed above, was estimated to induce a $\sim 20 \%$ underestimation of the $\mathrm{d} N_{\text {Acc }}$ calculated here, whilst it had a negligible impact on $\mathrm{d} N_{\text {UFP. }}$. The $\mathrm{d} N_{\text {UFP }}$ and $\mathrm{d} N_{\text {Acc }}$ obtained in correspondence of each SLR were used to calculate the ultrafine-to-accumulation ratio $\mathrm{d} N_{\mathrm{UFP}} / \mathrm{d} N_{\mathrm{Acc}}$.

The carbon monoxide $(\mathrm{CO})$ and ozone $\left(\mathrm{O}_{3}\right)$ mixing ratios were measured by the MOZART instrument $(\mathrm{CO}, 30$ s resolution and $\pm 5 \%$ nominal uncertainty, $\mathrm{O}_{3}, 4 \mathrm{~s}$ resolution and $\pm 2 \%$ nominal uncertainty) (Nedelec et al., 2003). Starting from the measured $\mathrm{O}_{3}$ and $\mathrm{CO}$, the ozone enhancement ratio $\left(\Delta \mathrm{O}_{3} / \Delta \mathrm{CO}\right)$ was calculated, i.e. the ratio of the ozone to carbon monoxide variations compared to their baseline values. A background value of $\sim 70 \mathrm{ppbv}$ in the boundary layer and $\sim 60 \mathrm{ppbv}$ in the free troposphere was used for $\mathrm{CO}$, while the background was set at $\sim 30$ ppbv for $\mathrm{O}_{3}$ at all levels (Di Biagio et al., 2015). $\Delta \mathrm{O}_{3} / \Delta \mathrm{CO}$ data were used together with $\mathrm{d} N_{\mathrm{UFP}} / \mathrm{d} N_{\text {Acc }}$ to retrieve information on the age of the sampled air masses, as discussed in Di Biagio et al. (2015).

In order to compare SLRs measurements obtained at different altitudes, the data analysed here were reported to standard temperature and pressure (STP) using $T=293.15 \mathrm{~K}$ and $P=1013.25 \mathrm{hPa}$. In this case, the scattering and absorption coefficients were scaled to STP conditions and the particle concentrations (in number or volume) were given as particles per standard $\mathrm{cm}^{-3}\left(\mathrm{scm}^{-3}\right)$. Where not explicitly indicated, data refer to STP conditions. 
In Table 2 we summarize main information and uncertainties for the different aerosol instruments considered in this study.

\subsection{Optical closure and estimation of the aerosol complex refractive index}

An optical closure study was realized to estimate the complex refractive index $(m=n-i k)$ of pollution aerosols based on optical and size data. The flowchart of the procedure is illustrated in Fig. 2. Optical closure consisted in recalculating the spectral scattering $\sigma_{\mathrm{s}}$ and absorption $\sigma_{\mathrm{abs}}$ coefficients measured for each SLR by using the measured size distribution as input and by varying the real $(n)$ and imaginary $(k)$ parts of the complex refractive index in the calculations. Then, $n$ and $k$ were fixed when the best agreement between measurements and calculations was found. Given that the size distribution measured by the PCASP and the GRIMM depends on the aerosol refractive index, the optical-to-geometrical diameter conversion was recalculated at each iteration based on the assumed $n$ and $k$. Optical calculations were performed using Mie theory for spherical particles. The Mie_single.pro IDL routine available at http://eodg.atm.ox.ac.uk/MIE/mie_single.html was used. In the calculations the real part of the refractive index was varied in the range $1.30-1.80$ at steps of 0.01 , while the imaginary part in the range $0.001-0.1$ at steps of 0.001 , for a total of 5100 inversions for each SLR data set. The uncertainty on the real and imaginary parts of the refractive index was estimated with a sensitivity study. To this purpose, the values of $n$ and $k$ were also obtained by using as input the observed $\sigma_{\mathrm{s}}, \sigma_{\mathrm{abs}}$, and $\frac{\mathrm{d} N}{\mathrm{~d} \log D_{\mathrm{g}}}$ plus or minus $1 \sigma$ standard deviation on their measurement. The deviations of the values of $n$ and $k$ retrieved in the sensitivity study with respect to those obtained in the first inversions were assumed to correspond to the $1 \sigma$ standard deviation uncertainty. The estimated uncertainty was $<5 \%$ for $n$ and $\sim 25-30 \%$ for $k$.

\subsection{Boundary layer height estimation}

The planetary boundary layer (BL) top height was estimated from meteorological observations (temperature, $T$, potential temperature, $\theta$, and relative humidity, $\mathrm{RH}$ ) for each vertical sounding performed during TRAQA flights (see Di Biagio et al., 2015). The boundary layer top height was between 730 and $1500 \mathrm{~m}$, with an average of $\sim 1000 \mathrm{~m}$. The location of each SLR, so if it is within the boundary layer or in the free troposphere, was determined based on the planetary boundary layer top height estimated from the closest vertical sounding performed during each flight.

\subsection{Tracking the origin of the sampled air masses}

As discussed in Di Biagio et al. (2015), aerosol observations during TRAQA were mostly influenced by pollution export from different sources around the basin (Northern
Italy/Po Valley, Southern France, Barcelona area). The Lagrangian trajectory model FLEXPART (FLEXible PARTicle dispersion model, Stohl et al., 1998), adapted for the WRF (Weather Research and Forecasting) meteorological input (Brioude et al., 2013) was used here to track the origin of air masses sampled during SLRs. Five-day three-dimensional back-trajectories were calculated using the WRF meteorological output at a $30 \mathrm{~km}$ horizontal resolution and 28 vertical model levels up to $50 \mathrm{hPa}$. The model specific humidity and potential vorticity were also interpolated along the trajectory path. Based on FLEXPART simulations, data for the different SLRs were separated as a function of the origin of the sampled air masses. Three different sectors were defined: the Western sector, which includes trajectories coming from the Atlantic Ocean and travelling over France or northern Spain before reaching the Western basin; the Eastern sector, including air mass trajectories from continental Europe that have travelled over northern Italy-Po Valley before entering the basin; and the Open sea sector, which consists of trajectories coming from the Western or Eastern sectors which have experienced at least 2 days of subsidence over the sea in the Western basin and thus can be taken as representative of the regional background aerosol or local pollution sources, i.e. ship emissions. The three different selected sectors are shown in Fig. 1, while Table 1 also reports the identified sector of origin for the air masses sampled during the different SLRs.

As discussed in Di Biagio et al. (2015), several flights were affected by dust particles exported over the basin from Northern Africa. SLRs data dominated by dust were identified based on the combined analysis of back-trajectories, lidar profiles and optical data, and were excluded from the data set. However, for some SLRs, the possible mixing of dust aerosols with pollution particles cannot be a priori excluded.

\subsection{Radiative model calculations}

Radiative transfer calculations were performed to estimate the instantaneous aerosol direct radiative effect in the shortwave spectral range for different cases and in clear-sky conditions. The objective of the calculations was to test the sensitivity of the DRE to the variability of the aerosol optical properties, in particular the single scattering albedo, as observed in this study. The GAME radiative transfer model (Dubuisson et al., 1996, 2006) was used in this study to compute the vertical profiles of downward and upward shortwave irradiances over the $0.28-3.0 \mu \mathrm{m}$ spectral range. The model calculates radiances and irradiances at various atmospheric levels at $400 \mathrm{~cm}^{-1}$ spectral resolution between 0.28 and $0.5 \mu \mathrm{m}$, and $100 \mathrm{~cm}^{-1}$ resolution between 0.5 and $3 \mu \mathrm{m}$. Spectral absorption by principal atmospheric gases $\left(\mathrm{H}_{2} \mathrm{O}, \mathrm{CO}_{2}, \mathrm{O}_{3}, \mathrm{CH}_{4}\right.$, $\mathrm{N}_{2} \mathrm{O}, \mathrm{O}_{2}$ ) is taken into account in the model. The discrete ordinate method (Stamnes et al., 1988) with 12 streams was used in the simulations to describe multiple scattering. Simulations were performed with and without aerosols by fixing 


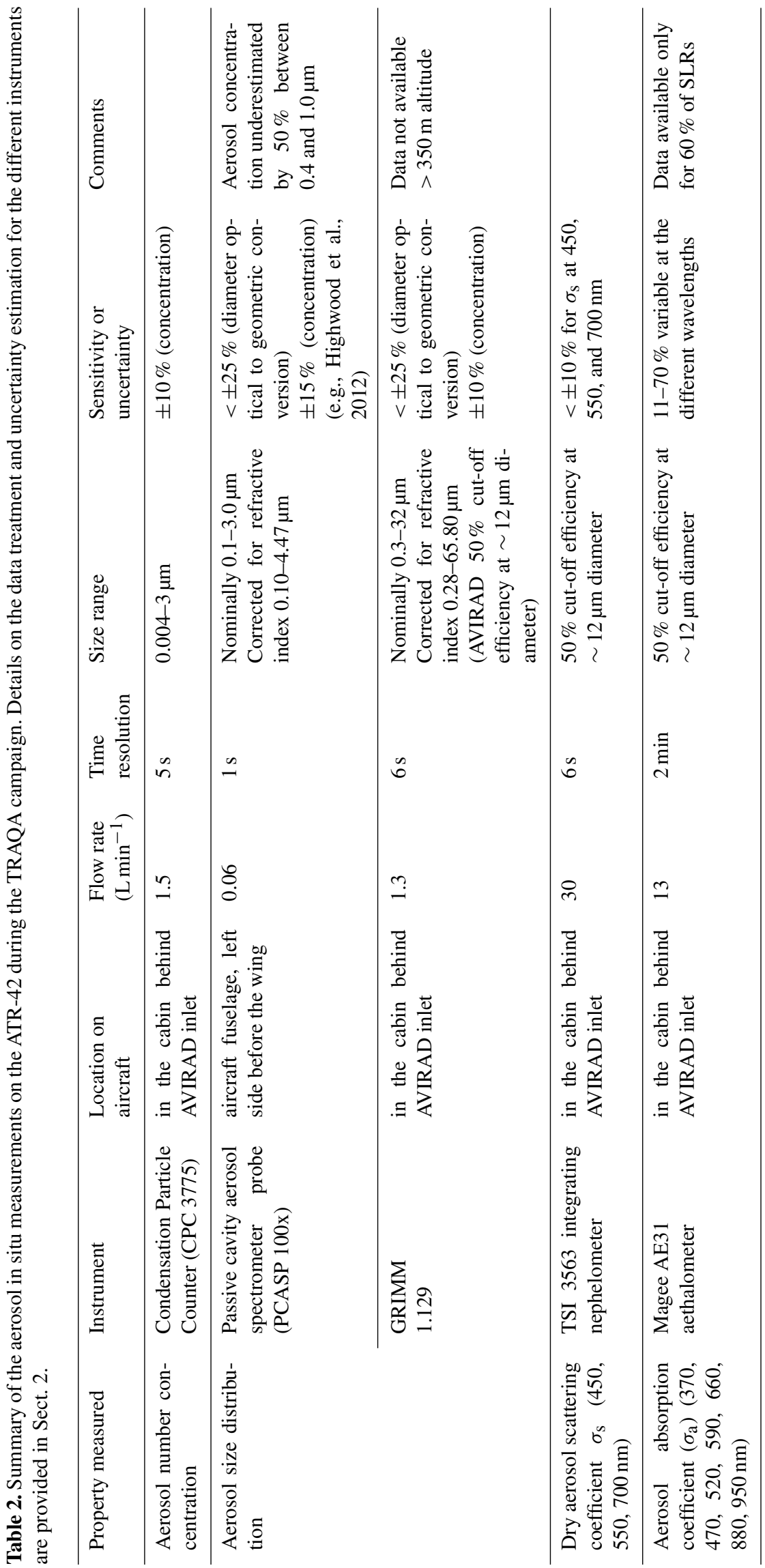




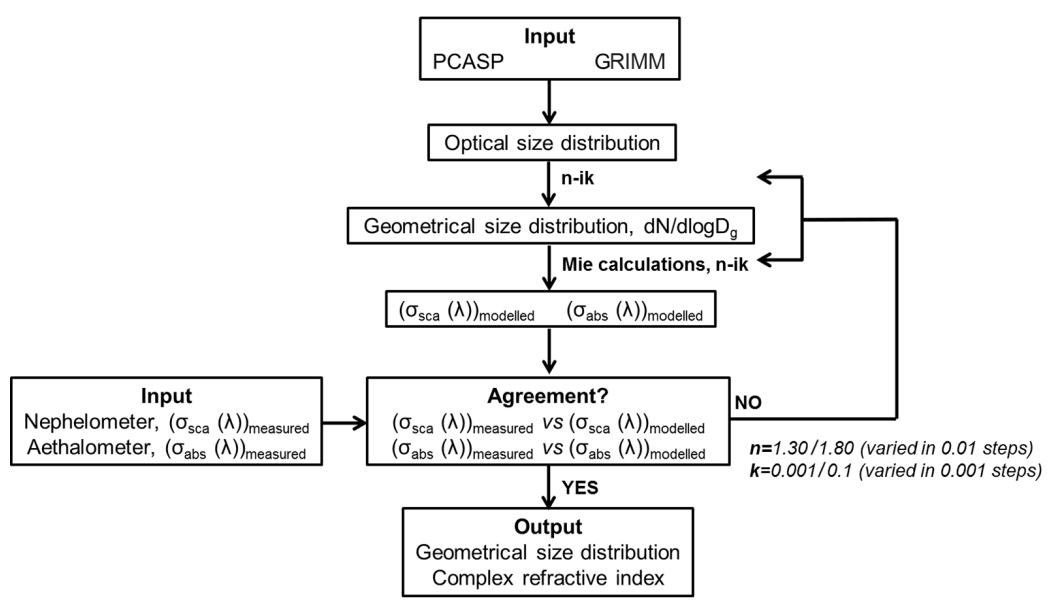

Figure 2. Flowchart of the size distribution and refractive index retrieval procedure. Further details are provided in Sect. 3.2.

the solar zenith angle $(\theta)$ at $60^{\circ}$, i.e. at about the mean of the diurnal value at the latitudes of north-Western Mediterranean, and for a mid-latitude climatological summer meteorological profile. The aerosol optical properties that are used as input in the GAME radiative code are the spectral variation of the optical depth $(\tau)$, the asymmetry parameter $(g)$ and the single scattering albedo $(\omega)$. The difference of the net shortwave fluxes (downward minus upward irradiances) with and without aerosols at the surface and at TOA was used to estimate the aerosol DRE at these two levels. The atmospheric DRE was then calculated as the difference between the TOA and the surface values. Finally, the ratio of the DRE to the aerosol optical depth at $500 \mathrm{~nm}$, i.e. the aerosol forcing efficiency (FE), was obtained. The shortwave heating rate at the altitude $\mathrm{z}$ was also calculated as

$\frac{\partial T}{\partial t}=-\frac{1}{\rho C_{p}} \frac{\partial F(z)}{\partial z}$

where $T$ is the air temperature, $\rho$ is the air density, $C_{p}$ is the specific heat of the air, and $F(z)$ is the net flux at the altitude $z$.

\section{Results}

\subsection{Overview over the different SLRs}

Figure 3 shows the average altitude, spectral scattering $\left(\sigma_{\mathrm{s}}\right)$ and absorption $\left(\sigma_{\mathrm{abs}}\right)$ coefficients, scattering and absorption Ångström exponent (SAE and AAE, respectively), ozone enhancement factor $\left(\Delta \mathrm{O}_{3} / \Delta \mathrm{CO}\right)$, and ultrafine-toaccumulation particle ratio $\left(\mathrm{d} N_{\mathrm{UFP}} / \mathrm{d} N_{\text {Acc }}\right)$ measured for the different SLRs during TRAQA.

As shown in Fig. 3 and Table 1, the large majority of the SLRs were performed within the boundary layer at an altitude $<1000 \mathrm{~m}$. Only four SLRs (V25_R2, V25_R3, V26_R1, and V30_R1) measured aerosols in the free troposphere between 1800 and $3500 \mathrm{~m}$. The sampled aerosols originated in each of the three different source sectors identified based on FLEXPART back-trajectories (Western, Eastern, and Open sea), with a larger number of cases from the Western sector compared to the Eastern and the Open sea areas.

For all the different cases, the measured scattering coefficient was in the range $16-73 \mathrm{Mm}^{-1}$ at $450 \mathrm{~nm}$ and $8_{-}^{-}$ $30 \mathrm{Mm}^{-1}$ at $700 \mathrm{~nm}$. The absorption coefficient was generally below $10 \mathrm{Mm}^{-1}$ at all wavelengths, with the exception of V27_R1 and V32_R1 for which values up to $\sim 20 \mathrm{Mm}^{-1}$ at $370 \mathrm{~nm}$ were measured. For these two cases also the highest values of the particle concentration in the accumulation mode $\left(\sim 1700-2200 \mathrm{~cm}^{-3}\right.$, not shown) and among the highest values of the scattering coefficient were measured. For all cases, both $\sigma_{\mathrm{s}}$ and $\sigma_{\mathrm{abs}}$ decrease with the wavelength. The pronounced spectral variability of $\sigma_{\mathrm{s}}$, in particular, indicates the dominance of fine particles in the sampled plumes.

The SAE varied between 0.96 and 1.94, while the AAE varied between 0.92 and 1.65 , with an average of $\sim 1.20$. The AAE was not calculated for few cases with very low values of the absorption coefficient $\left(\sigma_{\mathrm{abs}}\right.$ at $\left.370 \mathrm{~nm}<1.5 \mathrm{Mm}^{-1}\right)$. Both the SAE and the AAE obtained in this study fall in the range of variability indicated by several authors to identify pollution aerosols or pollution mixed with other aerosol types in the Mediterranean basin $(\mathrm{SAE}>1-1.5$, and $\mathrm{AAE} \sim 1-1.5$; Pace et al., 2006; Toledano et al., 2007; Mallet et al., 2013). Values of AAE larger than unity, in particular, might suggest the possible mixing of pollution with brown carbon or dust particles over the basin (Russell et al., 2010; Mallet et al., 2013).

For all the measured SLRs the $\Delta \mathrm{O}_{3} / \Delta \mathrm{CO}$ and the $\mathrm{d} N_{\mathrm{UFP}} / \mathrm{d} N_{\mathrm{Acc}}$ ratios varied in the range $0.37-1.02$ and 150, respectively, for $\mathrm{O}_{3}$ and $\mathrm{CO}$ varying between 24-78 and 69-136 ppbv and $\mathrm{d} N_{\mathrm{UFP}}$ and $\mathrm{d} N_{\mathrm{Acc}}$ between $320-22500$ and $100-2170 \# \mathrm{~cm}^{-3} . \Delta \mathrm{O}_{3} / \Delta \mathrm{CO}$ and the $\mathrm{d} N_{\mathrm{UFP}} / \mathrm{d} N_{\mathrm{Acc}}$ are linked to the photochemical (rate of ozone formation) and physical (rate of ultrafine to accumulation particle con- 


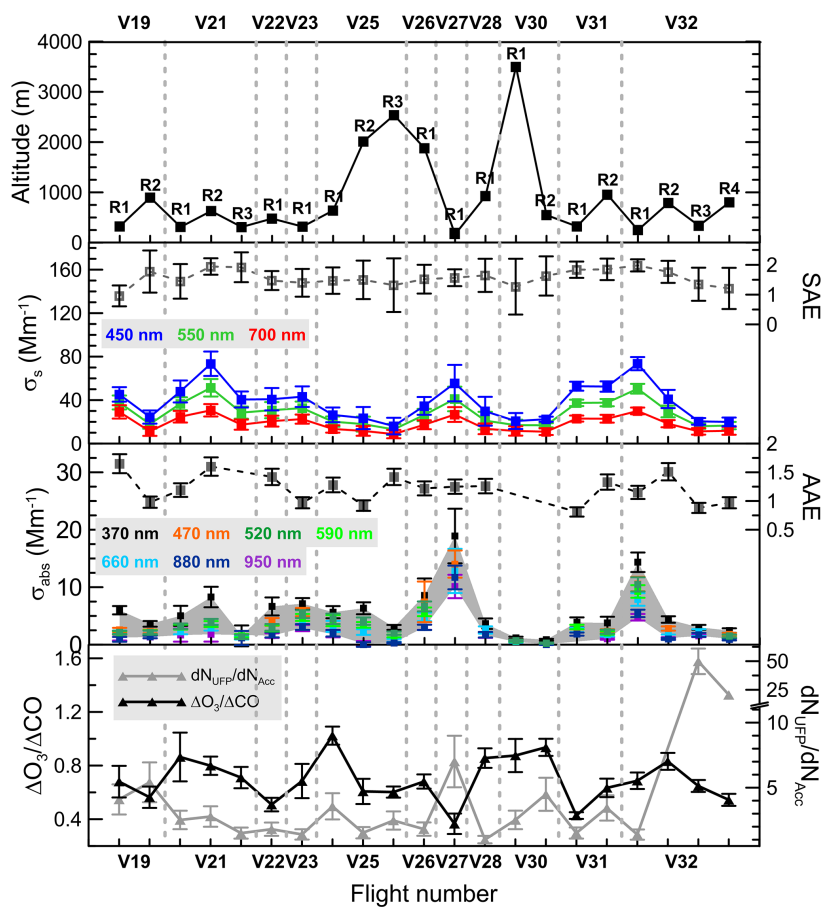

Figure 3. Averages over the different TRAQA straight levelled runs (SLRs) of the measured altitude, spectral scattering coefficient $\left(\sigma_{\mathrm{s}} ; 450,550\right.$, and $\left.700 \mathrm{~nm}\right)$, scattering Ångström exponent (SAE), spectral absorption coefficient $\left(\sigma_{\text {abs }} ; 370,470,520,590,660,880\right.$, and $950 \mathrm{~nm}$ ), absorption Ångström exponent (AAE), ozone enhancement factor $\left(\Delta \mathrm{O}_{3} / \Delta \mathrm{CO}\right)$ and ultrafine-to-accumulation ratio $\left(\mathrm{d} N_{\mathrm{UFP}} / \mathrm{d} N_{\mathrm{Acc}}\right)$. Uncertainties indicate the $1 \sigma$ standard deviation. The $x$ axis indicates the flight number (19 to 32 for flights V019 to V032); each point for the same flight number represents a different SLR.

version) processes responsible for the aging of the aerosol plumes. The range of measured values here includes both cases with high $\mathrm{d} N_{\mathrm{UFP}} / \mathrm{d} N_{\mathrm{Acc}}$ and low $\Delta \mathrm{O}_{3} / \Delta \mathrm{CO}$, typical of fresh plumes, and cases with low $\mathrm{d} N_{\mathrm{UFP}} / \mathrm{d} N_{\mathrm{Acc}}$ and high $\Delta \mathrm{O}_{3} / \Delta C \mathrm{C}$, indicative of more aged air masses (Di Biagio et al., 2015).

The summary of observations from Fig. 3 suggests that the set of SLRs measurements considered in this study can be considered representative of a wide range of different atmospheric conditions occurring over the basin both in terms of sources, loadings, and lifetimes for pollution aerosols.

\subsection{Particle size distributions}

Figure 4 shows the mean and the range of variability of the number and volume size distributions measured during horizontal SLRs within pollution layers during TRAQA. Data were separated based on the origin of the sampled air masses and refer only to cases at $<350 \mathrm{~m}$ altitude within the boundary layer. The absolute uncertainty on the measured concentration, as also reported in Table 2 , is $\sim 15 \%$ for particle di-
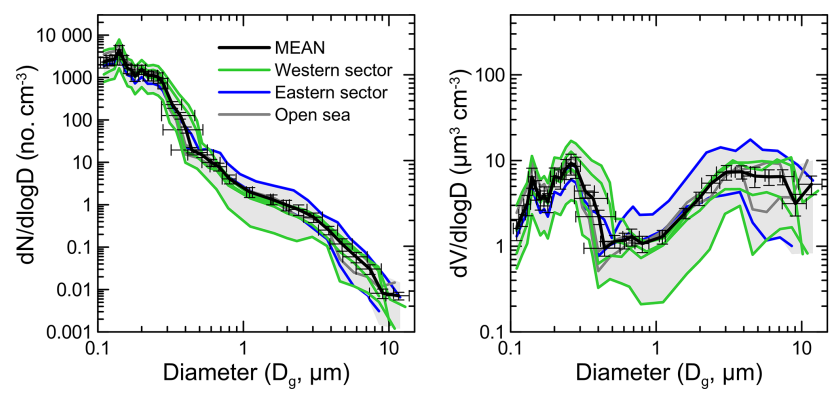

Figure 4. Number size distributions (left panel) and volume size distributions (right panel) measured over the different SLRs for the TRAQA flights. Data correspond to measurements performed within the boundary layer at altitudes $<350 \mathrm{~m}$ (V19_R1, V21_R1, V21_R3, V23_R2, V27_R1, V31_R1, V32_R1, V32_R3). Data are separated based on the different air mass origin (Western sector, Eastern sector, and Open sea). Concentrations are given at ambient conditions. Grey shading represents minimum and maximum measured values, while the black curve is the average size. Measurement uncertainties are also reported for the average curve.

ameters below $0.30 \mu \mathrm{m}$ and $\sim 10 \%$ at larger sizes. The grey shading indicates considerable variability in the number concentration of the size distributions, of approximately 1 order of magnitude for much of the size range measured. This reflects the relative wide range of aerosol loadings encountered during the campaign. The minimum of the size distribution over the whole diameter range was measured in the Western sector (V32_R3), whilst the largest number concentrations in the super-micron range were observed in correspondence of V19_R1 and V32_R1. For all the other SLRs, the size distributions were very similar, especially at diameters below $\sim 5 \mu \mathrm{m}$.

The measured number size distribution from each SLR was fitted with multi-mode lognormal functions:

$$
\frac{\mathrm{d} N}{\mathrm{~d} \log D_{\mathrm{g}}}=\sum_{i} \frac{N_{\mathrm{tot}, i}}{\sqrt{2 \pi} \log \sigma_{\mathrm{g}, i}}\left(-\frac{\left(\log D_{\mathrm{p}}-\log D_{\mathrm{g}, i}\right)^{2}}{2 \log ^{2} \sigma_{\mathrm{g}, i}}\right) .
$$

For each mode $i, N_{\text {tot }}$ represents the total aerosol number concentration, $D_{\mathrm{g}}$ the median diameter, and $\sigma_{\mathrm{g}}$ the geometric standard deviation. The logarithm refers to base 10 . Size data were fitted automatically using the MPCURVEFIT IDL routine available at http://www.physics.wisc.edu/ $\sim$ craigm/idl/fitting.html. Since the aim of the fitting is to describe as closely as possible the measured number size distributions for subsequent optical calculations (Sect. 4.4), up to seven modes were used to fit the data. The correlation coefficient for the fit functions was larger than 0.97 for all cases. The parameters of the lognormal fits are reported in Table 3. The first mode of the size distribution is generally at 0.13 $0.14 \mu \mathrm{m}$, whilst the largest mode is between $\sim 5$ and $8 \mu \mathrm{m}$ for the different cases. 
Table 3. Lognormal mode parameters of the measured aerosol size distribution (total aerosol number concentration, $N_{\text {tot }}$, median diameter, $D_{\mathrm{g}}$, and geometric standard deviation, $\sigma_{\mathrm{g}}$ ). Data correspond to SLRs below $\sim 350 \mathrm{~m}$ altitude. Diameters are given in microns and number concentrations are given in particles per $\mathrm{cm}^{-3}$ and refer to ambient conditions.

\begin{tabular}{|c|c|c|c|c|c|c|c|c|}
\hline & & Mode 1 & Mode 2 & Mode 3 & Mode 4 & Mode 5 & Mode 6 & Mode 7 \\
\hline \multirow[t]{3}{*}{ V19_R1 } & $N_{\text {tot }}$ & 498 & 160 & 12 & 4.0 & 1.6 & 0.04 & \\
\hline & $D_{\mathrm{g}}$ & 0.13 & 0.24 & 0.38 & 0.61 & 1.55 & 4.85 & \\
\hline & $\sigma_{\mathrm{g}}$ & 1.19 & 1.16 & 1.17 & 1.29 & 1.60 & 1.45 & \\
\hline \multirow[t]{3}{*}{ V21_R1 } & $N_{\text {tot }}$ & 600 & 210 & 2.0 & 5.5 & 0.65 & & \\
\hline & $D_{\mathrm{g}}$ & 0.13 & 0.24 & 0.37 & 0.48 & 1.35 & & \\
\hline & $\sigma_{\mathrm{g}}$ & 1.20 & 1.17 & 1.15 & 1.40 & 1.62 & & \\
\hline \multirow[t]{3}{*}{ V21_R3 } & $N_{\text {tot }}$ & 600 & 195 & 2.7 & 3.0 & 0.50 & 0.01 & \\
\hline & $D_{\mathrm{g}}$ & 0.13 & 0.23 & 0.35 & 0.51 & 1.45 & 4.50 & \\
\hline & $\sigma_{\mathrm{g}}$ & 1.19 & 1.21 & 1.18 & 1.38 & 1.66 & 1.41 & \\
\hline \multirow[t]{3}{*}{ V23_R2 } & $N_{\text {tot }}$ & 660 & 195 & 2.0 & 3.2 & 0.80 & 0.02 & \\
\hline & $D_{\mathrm{g}}$ & 0.13 & 0.23 & 0.37 & 0.53 & 1.45 & 5.69 & \\
\hline & $\sigma_{\mathrm{g}}$ & 1.19 & 1.16 & 1.16 & 1.37 & 1.65 & 1.25 & \\
\hline \multirow[t]{3}{*}{ V27_R1 } & $N_{\text {tot }}$ & 930 & 264 & 2.5 & 5.2 & 0.70 & 0.04 & 0.004 \\
\hline & $D_{\mathrm{g}}$ & 0.13 & 0.23 & 0.37 & 0.48 & 1.30 & 3. 50 & 8.20 \\
\hline & $\sigma_{\mathrm{g}}$ & 1.19 & 1.20 & 1.18 & 1.40 & 1.68 & 1.12 & 1.26 \\
\hline \multirow[t]{3}{*}{ V31_R1 } & $N_{\text {tot }}$ & 482 & 278 & 48 & 2.7 & 0.55 & 0.01 & \\
\hline & $D_{\mathrm{g}}$ & 0.14 & 0.24 & 0.35 & 0.54 & 1.82 & 7.14 & \\
\hline & $\sigma_{\mathrm{g}}$ & 1.20 & 1.16 & 1.17 & 1.39 & 1.65 & 1.17 & \\
\hline \multirow[t]{3}{*}{ V32_R1 } & $N_{\text {tot }}$ & 1135 & 413 & 55 & 5.0 & 0.65 & 0.01 & \\
\hline & $D_{\mathrm{g}}$ & 0.13 & 0.23 & 0.37 & 0.50 & 1.65 & 7.30 & \\
\hline & $\sigma_{\mathrm{g}}^{\circ}$ & 1.19 & 1.18 & 1.16 & 1.37 & 1.66 & 1.11 & \\
\hline \multirow[t]{3}{*}{ V32_R3 } & $N_{\text {tot }}$ & 235 & 8 & 8 & 3.2 & 0.15 & 0.02 & 0.002 \\
\hline & $D_{\mathrm{g}}$ & 0.14 & 0.28 & 0.28 & 0.40 & 1.42 & 3.29 & 7.21 \\
\hline & $\sigma_{\mathrm{g}}$ & 1.19 & 1.16 & 1.16 & 1.32 & 1.68 & 1.12 & 1.31 \\
\hline
\end{tabular}

\subsection{Spectral single scattering albedo: variability as a function of air mass origin and height}

Figure 5 shows the spectral $\omega$ for the different SLRs considered in this study. Data were separated based on the origin of the sampled air masses. The single scattering albedo varies in the range $0.84-0.98$ at $370 \mathrm{~nm}$ and $0.70-0.99$ at $950 \mathrm{~nm}$ and generally decreases with the wavelength, as it is typical for pollution particles (Dubovik et al., 2002). Only in two cases (V19_R1 and V30_R2) the single scattering albedo increases with wavelength. For these cases also very high values of $\omega$ were observed (0.92-0.97 for V19_R1 and 0.981.0 for V30_R2), which may suggest the possible mixing of pollution with sea spray or desert dust particles, both showing low absorption in the shortwave range (Bergstrom et al., 2007). The lowest values of the single scattering albedo were measured for V27_R1 (0.84-0.70 between 370 and $950 \mathrm{~nm})$ sampled at $\sim 160 \mathrm{~m}$ and originated in the Open Sea sector. Data in Fig. 3 also indicate for V27_R1 very low values of $\Delta \mathrm{O}_{3} / \Delta \mathrm{CO}(\sim 0.37)$ and a relatively high $\mathrm{d} N_{\mathrm{UFP}} / \mathrm{d} N_{\text {Acc }}$ $(\sim 7)$, which suggests that V27_R1 was a fresh plume possi- bly associated to local emissions, i.e. ship plumes, over the basin. If we exclude V27_R1, the range of measured values appears comparable (within error bars) for the three considered sectors (Western, Eastern, and Open sea; $\omega$ between 0.88 and 0.98 at $370 \mathrm{~nm}$ and 0.83 and 0.99 at $950 \mathrm{~nm}$ ).

The vertical variability of $\omega$, together with $\mathrm{d} N_{\mathrm{UFP}} / \mathrm{d} N_{\mathrm{Acc}}$, $\Delta \mathrm{O}_{3} / \Delta \mathrm{CO}$, SAE, and AAE, is shown in Fig. 6 for the different considered cases. With the only exception of V27_R1, for which the lowest values were observed below $200 \mathrm{~m}$, the single scattering albedo does not show a clear trend with height, with a similar range of values measured in the boundary layer, below $\sim 1000 \mathrm{~m}$, and in the free troposphere up to $\sim 3500 \mathrm{~m}$. As for $\omega$, the AAE does not significantly vary with height. At the same time, $\mathrm{d} N_{\mathrm{UFP}} / \mathrm{d} N_{\mathrm{Acc}}$ and SAE decrease with height, with a concurrent slight $\Delta \mathrm{O}_{3} / \Delta \mathrm{CO}$ increase, which may suggest an increase of plume age with height. The ensemble of these observations seems to indicate that, for our observed cases, the absorptivity properties of the sampled plumes do not depend on the altitude and associated air mass age of the plume. It should be pointed out, however, that the majority of cases considered here were sampled be- 

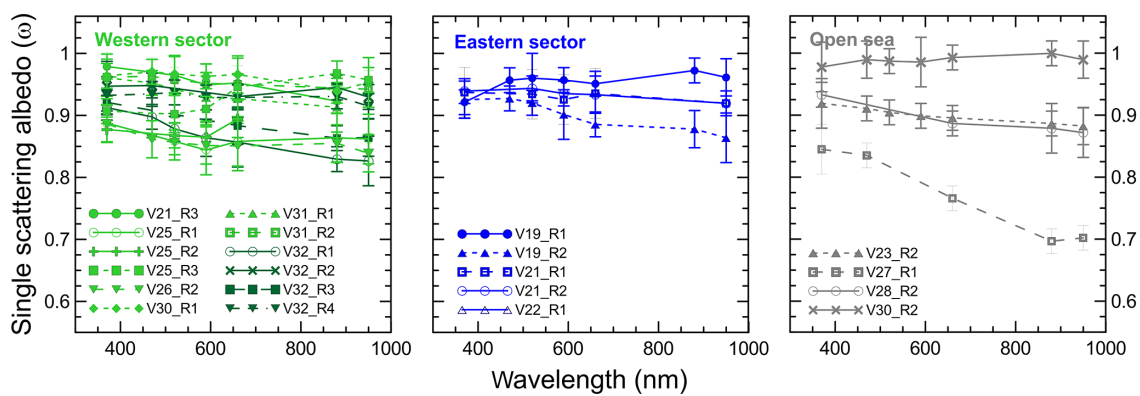

Figure 5. Spectral single scattering albedo at seven wavelengths between 370 and $950 \mathrm{~nm}$ calculated from nephelometer and aethalometer measurements for the different SLRs within pollution layers. Data are separated based on the different air mass origin (Western sector, Eastern sector, and Open sea).

low $1000 \mathrm{~m}$, so in the boundary layer, and the statistics in the free troposphere is only limited to a few events.

Values of the single scattering albedo measured in this study are comparable with values reported at several other sites in the Central and Western Mediterranean region for pollution aerosols (Mallet et al., 2003, 2013; Meloni et al., 2006; Saha et al., 2008; Di Biagio et al., 2009; Pandolfi et al., 2011). The single scattering albedo from these studies varies in the range $0.84-0.95$ at $440 \mathrm{~nm}, 0.76-0.98$ at 500 $550 \mathrm{~nm}$, and $0.80-0.87$ at $870 \mathrm{~nm}$. Compared with the literature, larger and lower values are obtained in the present study for few cases mostly influenced by sea spray, desert dust, and local fresh emissions, respectively.

\subsection{Complex refractive index of pollution aerosols}

As discussed in the previous section, the single scattering albedo of pollution aerosols shows a relatively large variability. Here we investigate the impact of this variability on the complex refractive index $(m=n-i k)$ of the particles.

For eight selected SLRs for which both complete optical (scattering and absorption coefficients, and single scattering albedo) and size distribution measurements were available, the aerosol spectral complex refractive index was estimated by optical closure study as described in Sect. 3.2. These cases correspond to V19_R1, V21_R1, V21_R3, V23_R2, V27_R1, V31_R1, V32_R1, V32_R3 sampled within the boundary layer at $<350 \mathrm{~m}$ altitude.

The comparison of the measured and modelled $\sigma_{\mathrm{s}}$ and $\sigma_{\mathrm{abs}}$ is shown in Fig. 7, while the retrieved real and imaginary parts of the refractive index for the different SLRs are reported in Fig. 8. Data in Fig. 8 are also compared to the real and imaginary parts of the refractive index for the single components (insoluble, water soluble, soot, and sea salt) considered in the OPAC model (Optical Properties of Aerosols and Clouds, Hess et al., 1998) to represent continental, urban and maritime polluted aerosols. As shown in Fig. 7, a very good agreement was found between the calculated and the measured scattering and absorption coefficients, with an average difference of less than $5 \%$ for both $\sigma_{\mathrm{s}}$ and $\sigma_{\mathrm{abs}}$. For

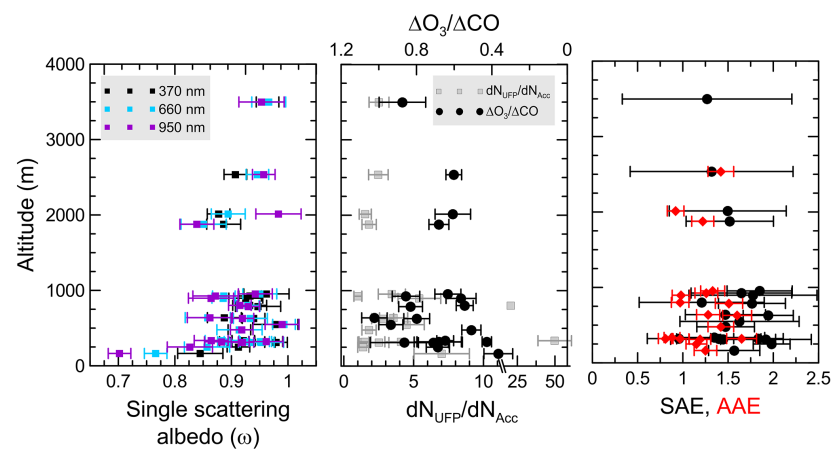

Figure 6. Single scattering albedo $(370,660$, and $950 \mathrm{~nm})$, ozone enhancement factor $\left(\Delta \mathrm{O}_{3} / \Delta \mathrm{CO}\right)$, ultrafine-to-accumulation ratio $\left(\mathrm{d} N_{\mathrm{UFP}} / \mathrm{d} N_{\mathrm{Acc}}\right)$, and scattering (SAE) and absorption Ångström exponent (AAE) versus height for all analysed SLRs cases. Uncertainties on measured and retrieved quantities (horizontal bars) are also shown in the plots.

our analysed cases $n$ and $k$ vary in the range 1.67-1.75 and $0.004-0.050$ at $370 \mathrm{~nm}$ and $1.41-1.77$ and $0.002-0.097$ at $950 \mathrm{~nm}$, respectively. The imaginary part of the refractive index slightly increases with wavelength, while not a clear tendency is found for the real part, which in some of the cases increases with wavelength and in others decreases. Highest values of $k$ are obtained for V27_R1, which also shows the absolute lowest values of $\omega$ in our data set (0.84-0.70), followed by V32_R1 and V32_R3, which also present relatively low values of $\omega(0.92-0.83)$. The lowest $k$, as well as among the lowest $n$, is instead obtained for V19_R1 $(\omega=0.92-$ 0.96). The comparison of our data with OPAC values for single components suggests that in most cases particles are composed of a mixing of insoluble and water-soluble components, with possible contributions of soot (V27_R1) ad sea salt (V19_R1).

The results of the complex refractive index obtained in this study are in agreement with previous estimates obtained for pollution aerosols in continental Europe $(n \sim 1.50-1.72$ and $k \sim 0.001-0.1$ for UV-visible wavelengths e.g. Ebert et al., 2002, 2004; Müller et al., 2002; Mallet et al., 2003, 2011; 

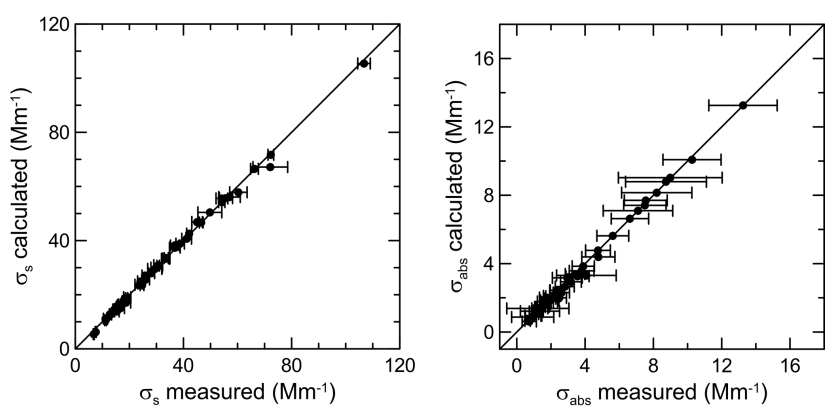

Figure 7. Comparison of the aerosol scattering ( $\sigma_{\mathrm{s}}$, left panel) and absorption $\left(\sigma_{\mathrm{abs}}\right.$, right panel) coefficients measured by the nephelometer and the aethalometer and calculated from measured size distribution data with Mie theory for an optimized refractive index. Data are given at ambient conditions. Uncertainties on the measured (horizontal bars) scattering and absorption coefficients are also shown in the plots.

Raut and Chazette, 2008). Larger values of both $n$ and $k$ are instead obtained here compared to AERONET retrievals at different sites in the Western Mediterranean (1.38-1.46 for $n$ and 0.003-0.01 for $k$ at 440 and $670 \mathrm{~nm}$; Mallet et al., 2013).

Figure 9 shows the results of the correlation analysis between the single scattering albedo and the complex refractive index obtained for the analysed cases. For the real part, the range of retrieved $n$ values is larger (1.41-1.74) for $\omega$ greater than $\sim 0.95$, while as the single scattering albedo decreases the real part converges to $\sim 1.65-1.75$ at all wavelengths. A strong correlation is observed between $\omega$ and $k$ at all wavelengths, that is the lower the single scattering albedo, the higher the imaginary part. A linear regression fit was applied to the $\omega-k$ data sets at the seven wavelengths. The slope of the fit varies between -2.2 and -6.9 , and decreases with the wavelength (in particular if the outlier points of $k$ in correspondence of V27_R1 are eliminated), in agreement with the decrease of $\omega$ with $\lambda$ for pollution aerosols. The intercept for all cases is lower than 1 (0.93-0.97), with lowest values obtained at 880 and $950 \mathrm{~nm}$. This is possibly associated to a slight underestimation of $\omega$ which, especially at these wavelengths, is difficult to determine given the high uncertainty on the particle absorption coefficient. Another source of uncertainty is the size distribution, which influences the results of Mie calculations, and thus has a direct impact on the refractive index retrieval.

\subsection{Influence of the single scattering albedo variability on the aerosol direct shortwave radiative effect (DRE)}

Radiative transfer model calculations with the GAME model were performed with the aim of investigating the impact of the variable optical properties, and in particular the single scattering albedo, on the shortwave direct radiative effect of pollution particles in the Western Mediterranean basin.
Simulations were performed by considering three different vertical aerosol profiles, based on observations reported by Di Biagio et al. (2015): (i) aerosols only confined in the BL (whose altitude is fixed at $1000 \mathrm{~m}$, in the mean of observations during TRAQA); (ii) $50 \%$ of the aerosol optical depth in the BL and $50 \%$ in the FT (which is considered to extend between 1000 and $4000 \mathrm{~m}$ ); (iii) $20 \%$ of the aerosol optical depth in the BL and $80 \%$ in the FT. For the different cases we fixed the total aerosol optical depth at 0.2 at $550 \mathrm{~nm}$, which corresponds to the mean of observations obtained over the Western basin during TRAQA (Di Biagio et al., 2015). However, results will be given as FE, so they are independent on the chosen optical depth. We assumed a uniform aerosol distribution and constant optical properties within the BL and the FT for the three different considered profiles. This assumption comes from the observations of the present study, which do not evidence any significant change of the aerosol properties with height. Aerosol spectral optical properties, both in the BL and in the FT up to $4000 \mathrm{~m}$, were assumed from observations, as explained in the following.

The GAME model requires as input the aerosol optical depth, single scattering albedo, and asymmetry factor at 7 wavelengths between 330 and $1500 \mathrm{~nm}$. The spectral optical depth between 330 and $1500 \mathrm{~nm}$ was extrapolated from the fixed value of 0.2 at $550 \mathrm{~nm}$ by assuming an Ångström exponent of 1.5, in the mean of our observations for pollution aerosols (see Fig. 3). For the single scattering albedo, we considered three different sets of values which correspond to the minimum, maximum, and mean of the values observed in this study (the absolute minimum for V27_R1 was excluded for calculations since it represents an outlier in our data). The $\omega$ values at $370-950 \mathrm{~nm}$ as obtained from experimental data were then extrapolated at the 7 GAME wavelengths (Table 4). The asymmetry factor was calculated from Mie theory based on the refractive index values and size distribution data for the eight cases considered in the previous Section. The spectral variation of $g$ used in the radiative transfer calculations was estimated as the mean of the values obtained for these eight cases extrapolated at the 7 GAME wavelengths. The obtained $\mathrm{g}$ varied between 0.60 at $330 \mathrm{~nm}$ and 0.51 at $1500 \mathrm{~nm}$. These values are consistent with previous estimates of $\mathrm{g}$ obtained for pollution aerosols over the Mediterranean basin (Meloni et al., 2006; Saha et al., 2008; Mallet et al., 2011).

Background stratospheric aerosols (above $12 \mathrm{~km}$ ) were also taken into account for radiative calculations; optical properties from the OPAC stratospheric aerosol model (Hess et al., 1998) were assumed.

Finally, in addition to aerosol optical properties, the GAME model requires as input the albedo of the surface $\left(A_{\mathrm{S}}\right)$ at 5 wavelengths between 448 and $2130 \mathrm{~nm}$. In this study, simulations were performed over the sea surface. The albedo of the sea surface was obtained from Jin et al. (2004), which provide a parameterization of $A_{\mathrm{S}}$ as a function of chlorophyll concentration $(\mathrm{Chl})$, wind speed $(w)$, aerosol optical depth at 

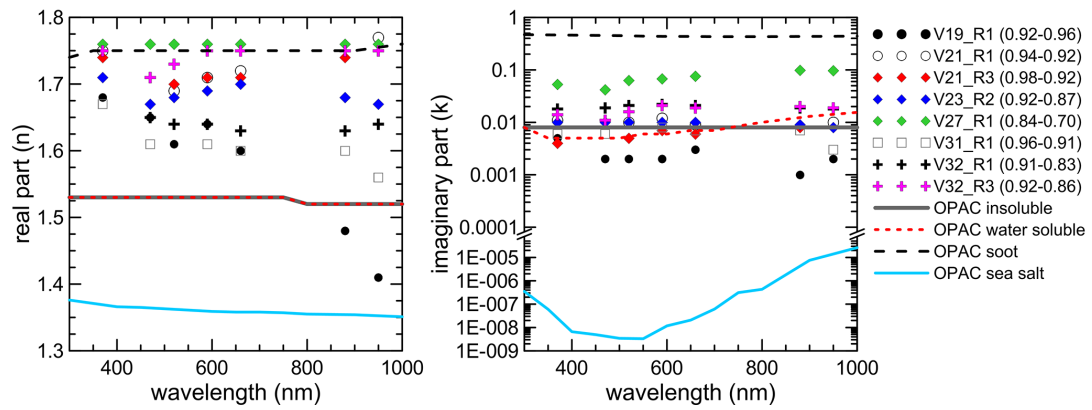

Figure 8. Spectral real ( $n$, left panel) and imaginary ( $k$, right panel) parts of the complex refractive index obtained by optical closure for the eight selected case studies. For the sake of clarity, uncertainties on $n$ and $k$ are not reported in the plot. The values of the single scattering albedo measured at 370 and $950 \mathrm{~nm}$ for the different cases are reported in the legend. The spectral real and imaginary parts of the complex refractive index as obtained from the Optical Properties of Aerosols and Clouds (OPAC, Hess et al., 1998) database for insoluble, water soluble, soot and sea salt components are also reported in the plot. These components are used in OPAC to model continental polluted, continental rural, urban, and maritime polluted aerosols.

Table 4. Maximum, mean, and minimum of the single scattering albedo considered for radiative transfer calculations. Values are reported at the seven wavelengths used as inputs in the GAME model.

\begin{tabular}{lrrrrrrr}
\hline & $330 \mathrm{~nm}$ & $400 \mathrm{~nm}$ & $550 \mathrm{~nm}$ & $670 \mathrm{~nm}$ & $870 \mathrm{~nm}$ & $1020 \mathrm{~nm}$ & $1500 \mathrm{~nm}$ \\
\hline$\omega$ max & 0.98 & 0.98 & 0.99 & 0.99 & 1.00 & 0.99 & 0.99 \\
$\omega$ mean & 0.93 & 0.93 & 0.92 & 0.91 & 0.90 & 0.90 & 0.89 \\
$\omega$ min & 0.88 & 0.87 & 0.85 & 0.85 & 0.83 & 0.82 & 0.80 \\
\hline
\end{tabular}

$500 \mathrm{~nm}(\tau)$, and the solar zenith angle $(\theta)$. For this study $\mathrm{A}_{S}$ was estimated for $\mathrm{Chl}=0, w=6-9 \mathrm{~m} \mathrm{~s}^{-1}, \tau=0.24$ (extrapolated from the value of 0.2 at $550 \mathrm{~nm}$ ), and $\theta=60^{\circ}$, and it varied between 0.009 and 0.005 in the considered 448$2130 \mathrm{~nm}$ spectral range.

Results of the radiative transfer simulations are shown in Fig. 10, which reports the FE at the surface, TOA, and atmosphere $\left(\mathrm{FE}_{\mathrm{S}}, \mathrm{FE}_{\mathrm{TOA}}\right.$ and $\mathrm{FE}_{\mathrm{ATM}}$ ) for the maximum, mean, and minimum of the single scattering albedo observed in this study. Results of the simulations are mostly independent on the vertical distribution of the aerosols (less than $\sim 5 \%$ changes for $\mathrm{FE}_{\mathrm{S}}, \mathrm{FE}_{\mathrm{ATM}}$, and $\mathrm{FE}_{\mathrm{TOA}}$ for the three different profiles used in the simulations), so the mean of the results obtained for the three cases is reported in Fig. 10. The forcing efficiency varies between -160 and $-235\left(\mathrm{FE}_{\mathrm{S}}\right),-137$ and $-92\left(\mathrm{FE}_{\mathrm{TOA}}\right)$, and +23 and $+143\left(\mathrm{FE}_{\mathrm{ATM}}\right) \mathrm{W} \mathrm{m}^{-2} \tau^{-1}$ for $\omega$ varying between its maximum and minimum values. Estimates of the forcing efficiencies in correspondence of the mean of $\omega$ are $-198,-113$, and $+85 \mathrm{~W} \mathrm{~m}^{-2} \tau^{-1}$ at the surface, TOA, and atmosphere, respectively. The corresponding instantaneous shortwave heating rate at the surface varies between 0.2 and $2.0 \mathrm{~K} \mathrm{day}^{-1}$ for $\omega$ between its maximum and minimum.

As expected, the lower the single scattering albedo, the larger in absolute value the $\mathrm{FE}_{\mathrm{S}}$ and $\mathrm{FE}_{\mathrm{ATM}}$ and the lower the $\mathrm{FE}_{\mathrm{TOA}}$. This is due to the impact of absorption on the amount of radiation trapped in the atmosphere and transmitted towards the surface, which thus enhance the radiative ef- fect in the atmosphere and at the surface for decreasing $\omega$. Conversely, the larger the particle absorption, the lower the effect on the radiation reflected back to space, and thus the decrease of the intensity of the cooling effect at the TOA. Changes in the single scattering albedo of the particles between its maximum and minimum $(\Delta \omega=0.1-0.2$ at the different wavelengths) determine about a $50 \%$ strengthening of the direct shortwave radiative effect at the surface, and a reduction of $\sim 30 \%$ the effect at the TOA. Consequently, the atmospheric FE may vary up to an order of magnitude. These results thus highlight the sensitivity of the DRE on the absorptivity properties of the particles, as well as the importance of accurately reproducing the single scattering albedo of aerosols to correctly evaluate their direct radiative effect.

The results of the present study are in quite good agreement with previous estimates of the aerosol forcing efficiency for pollution aerosols in the Mediterranean area. $\mathrm{FE}_{\mathrm{S}}$, $\mathrm{FE}_{\mathrm{ATM}}$, and $\mathrm{FE}_{\mathrm{TOA}}$ obtained here compare well with data obtained in the Central Mediterranean by Di Biagio et al. (2009, 2010), who provide estimates based only on observational data, i.e. without any assumption on the aerosol optical properties. In these studies they report a forcing efficiency of $\sim-200$ and $-164 \mathrm{~W} \mathrm{~m}^{-2} \tau^{-1}$ at the surface and TOA at solar zenith angles of 50-60 for mixed aerosols (pollution plus sea salt particles). They estimate an increase in absolute value of $\mathrm{FE}_{\mathrm{S}}$ of about $20-40 \%$ due to a decrease of $0.1-0.2$ of the single scattering albedo (at 415 and $868 \mathrm{~nm}$ ) of the aerosols, as well as a concurrent increase of FETOA 

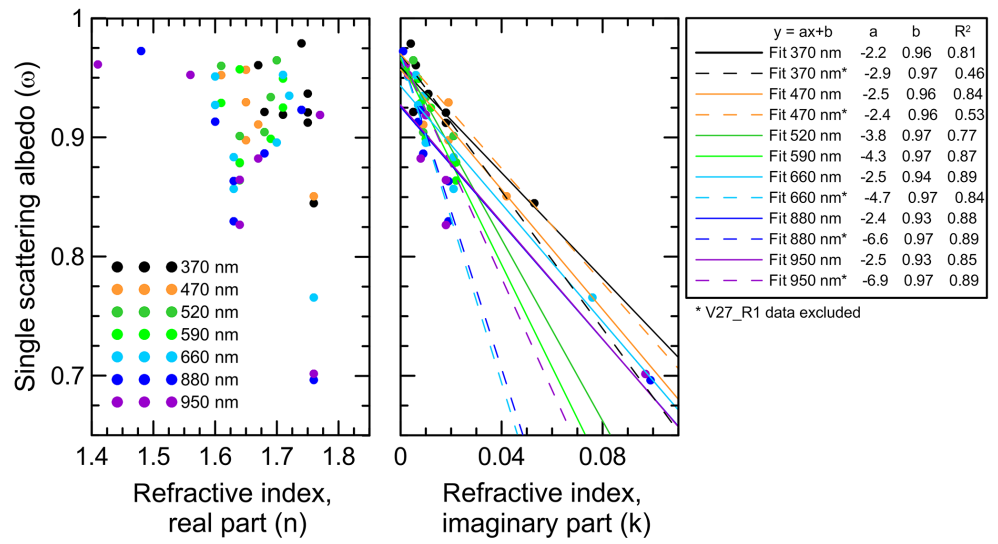

Figure 9. Spectral single scattering albedo plotted against the real (left panel) and the imaginary (right panel) parts of the complex refractive index. The results of the linear fit between $\omega$ and $k$ are reported in the legend. The fits are performed for the whole $\omega-k$ data set, and also eliminating the data in correspondence of V27_R1, for which the largest values of $k$ were observed.

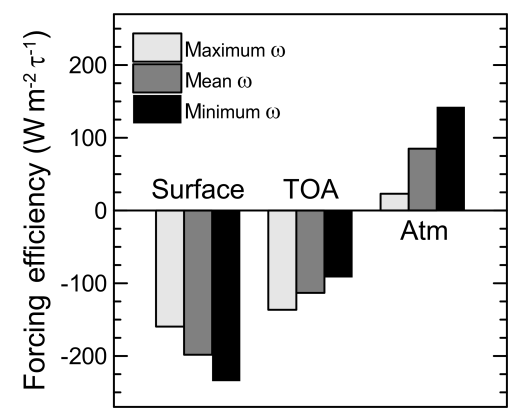

Figure 10. Aerosol shortwave forcing efficiency at $60^{\circ}$ solar zenith angle calculated at the surface, TOA, and within the atmosphere for the maximum, mean, and minimum of the single scattering albedo $(\omega)$ observed in this study (Table 4).

of about $10-40 \%$. The observations obtained in this study fall in the range of variability reported by Di Biagio et al. $(2009,2010)$. Our data also agree with estimates of Saha et al. (2008), reporting for pollution aerosols measured in the French Mediterranean coast up to $40 \%$ variability in the $\mathrm{FE}_{\mathrm{S}}$ and $\mathrm{FE}_{\mathrm{TOA}}$, concurrently with $70 \%$ increase of $\mathrm{FE}_{\mathrm{ATM}}$, due to a $\omega$ change of 0.15 at $525 \mathrm{~nm}$. Conversely, our estimates at the surface and TOA are larger in absolute value compared to data reported for continental Europe by Horvath et al. (2002), who estimated a $\mathrm{FE}_{\mathrm{S}}$ of $\sim-164 \mathrm{~W} \mathrm{~m}^{-2} \tau^{-1}$ and a $\mathrm{FE}_{\mathrm{TOA}}$ of $-50 \mathrm{~W} \mathrm{~m}^{-2} \tau^{-1}$ for polluted aerosols with $\omega=0.90$ at $520 \mathrm{~nm}$, thus comparable with our mean values of single scattering albedo for pollution aerosols.

\section{Conclusions}

In this study we have presented measurements of the spectral optical properties (scattering and absorption coefficients and single scattering albedo) and particle size distributions for pollution aerosols obtained over the remote sea in the
Western Mediterranean basin during the TRAQA campaign in summer 2012. The set of observations analysed in this study can be assumed to be representatives of a wide range of different conditions that can be observed over the basin, both in terms of pollution sources, aerosol loadings, and lifetimes of the plumes. The detailed characterization of the spectral optical properties of pollution aerosols in the Western basin was missing to date.

Observations from the present study show a large variability of the optical properties of pollution aerosols over the basin, in particular the single scattering albedo. Values of $\omega$ in the range $0.84-0.98$ at $370 \mathrm{~nm}$ and $0.70-0.99$ at $950 \mathrm{~nm}$ are observed in this study. This variability of $\omega$ does not seem to be clearly linked neither to the particle origin, nor to the altitude and associated aging of the sampled plumes. The variability of $\omega$ reflects in a large variability for the complex refractive index of pollution aerosols, which is estimated to span in the range 1.41-1.77 for the real part and 0.0020.097 for the imaginary part between 370 and $950 \mathrm{~nm}$. The analysis of the complex refractive index suggests that possible differences in terms of particle composition can explain in part the observed variability of $\omega$. A large range of compositions has been however reported for pollution aerosols in Europe and the Mediterranean basin (Mallet et al., 2003; Ebert et al., 2004; Pey et al., 2010; Piazzola et al., 2012) and a more detailed analysis of the aerosol composition for the cases measured here should be addressed.

Based on the observations of the present study, the variability of optical properties for pollution aerosols can arise from the combination of different factors, linked to the origin, production mechanism, and aging of the plumes along their lifetime, as well as the possible mixing of different plumes with different characteristics. So, the inherent heterogeneity of sources, coexistence of different air masses, and multiple physical and chemical processes occurring in a complex environment such as the Western Mediterranean 
may give rise to this inherent variability of the particle single scattering albedo.

This observed variability on $\omega$ has a large influence on the direct shortwave radiative effect of pollution aerosols at the surface, TOA, and within the atmosphere. For instance, a change of up to an order of magnitude (from +23 to $+143 \mathrm{~W} \mathrm{~m}^{-2} \tau^{-1}$ at $60^{\circ}$ solar zenith angle) in the atmospheric radiative effect is estimated due to the variability of the single scattering albedo within the range of values observed in this study. The change in the amount of atmospheric absorbed solar radiation may have a strong impact on the temperature profile and the atmospheric thermal structure, with important consequences on several processes, such as cloud formation and precipitations. The strong sensitivity of the DRE also at the surface, up to $50 \%$ for varying $\omega$, on its turn, may largely impact the rate of evaporation over the basin, which is also a crucial component of the hydrological cycle (Nabat et al., 2015). Given the large sensitivity of the Mediterranean area and the high risk of desertification for this region (Giorgi and Lionello, 2008; IPCC, 2013) any factor possibly impacting the hydrological cycle should be taken carefully into account by regional climate models. In this view, results from the present study can be used to provide a constraint of the absorption properties of pollution particles in the Western Mediterranean basin to use in regional modelling studies. Constraining these properties constitutes a crucial step in order to better assess the role of aerosols on the radiative balance of this region and to ameliorate the capability of making projection on future climate changes.

\section{Data availability}

The AVIRAD and ATR-42 data for the TRAQA campaign are available on the ChArMEx database at http://mistrals. sedoo.fr/ChArMEx/. The user must register before having access to the data.

Author contributions. Jean-Luc Attié, François Ravetta, Gerard Ancellet, and Paola Formenti designed the TRAQA experiment and coordinated the campaign. Cécile Gaimoz, Noel Grand, and Claudia Di Biagio operated the instruments on board the ATR-42 during the flights. Claudia Di Biagio performed the data analysis with contributions from Lionel Doppler and Paola Formenti. Silvia Bucci and Federico Fierli performed the FLEXPART simulations. Marc Mallet and Philippe Dubuisson provided the GAME code for radiative calculations. Claudia Di Biagio wrote the manuscript with contributions from all co-authors.

Acknowledgements. All measurement presented here are from the Chemistry-Aerosol Mediterranean Experiment project (ChArMEx, http://charmex.lsce.ipsl.fr), which is the atmospheric component of the French multidisciplinary program MISTRALS (Mediterranean Integrated Studies aT Regional And Local Scales). ChArMExFrance was principally funded by INSU, ADEME, ANR,
CNES, CTC (Corsica region), EU/FEDER, Météo-France, and CEA. TRAQA was funded by ADEME/PRIMEQUAL and MISTRALS/ChArMEx programmes and Observatoire Midi-Pyrénées. Claudia Di Biagio thanks the Centre National des Etudes Spatiales (CNES) for financial support.

The authors wish to thank the technicians, pilots and ground crew of SAFIRE (Service des Avions Francais Instruments pour la Recherche en Environnement) for facilitating the instrument integration and conducting flying operations. We thank S. Chevaillier, R. Loisil, J. Pelon, and P. Zapf for their contribution during the campaign. We also wish to thank G. Siour for his help to run the GAME radiative code. Helpful comments and suggestions by two anonymous reviewers are acknowledged.

Edited by: E. Gerasopoulos

Reviewed by: two anonymous referees

\section{References}

Anderson, T. L. and Ogren, J. A.: Determining aerosol radiative properties using the TSI 3563 integrating nephelometer, Aerosol Sci. Tech., 29, 57-69, 1998.

Arnott, W., Hamasha, K., Moosmüller, H., Sheridan, P. J., and Ogren, J. A.: Towards aerosol light-absorption measurements with a 7-wavelength aethalometer: Evaluation with a photoacoustic instrument and 3-wavelength nephelometer, Aerosol Sci. Tech., 39, 17-29, 2005.

Bergstrom, R. W., Pilewskie, P., Russell, P. B., Redemann, J., Bond, T. C., Quinn, P. K., and Sierau, B.: Spectral absorption properties of atmospheric aerosols, Atmos. Chem. Phys., 7, 5937-5943, doi:10.5194/acp-7-5937-2007, 2007.

Boucher, O.,Randall, D., Artaxo, P., Bretherton, C., Feingold, G., Forster, P., Kerminen, V.-M., Kondo, Y., Liao, H., Lohmann, U., Rasch, P., Satheesh, S. K., Sherwood, S., Stevens, B., and Zhang, X. Y.: Clouds and Aerosols, Climate Change 2013: The Physical Science Basis. Contribution of Working Group I to the Fifth Assessment Report of the Intergovernmental Panel on Climate Change, edited by: Stocker, T. and Qin, D., Cambridge Univ. Press, Cambridge, United Kingdom and New York, NY, USA, 2013.

Brioude, J., Arnold, D., Stohl, A., Cassiani, M., Morton, D., Seibert, P., Angevine, W., Evan, S., Dingwell, A., Fast, J. D., Easter, R. C., Pisso, I., Burkhart, J., and Wotawa, G.: The Lagrangian particle dispersion model FLEXPART-WRF version 3.1, Geosci. Model Dev., 6, 1889-1904, doi:10.5194/gmd-61889-2013, 2013.

Collaud Coen, M., Weingartner, E., Apituley, A., Ceburnis, D., Fierz-Schmidhauser, R., Flentje, H., Henzing, J. S., Jennings, S. G., Moerman, M., Petzold, A., Schmid, O., and Baltensperger, U.: Minimizing light absorption measurement artifacts of the Aethalometer: evaluation of five correction algorithms, Atmos. Meas. Tech., 3, 457-474, doi:10.5194/amt-3-457-2010, 2010.

Di Biagio, C., di Sarra, A., Meloni, D., Monteleone, F., Piacentino, S., and Sferlazzo, D.: Measurements of Mediterranean aerosol radiative forcing and influence of the single scattering albedo, J. Geophys. Res., 114, D06211, doi:10.1029/2008JD011037, 2009.

Di Biagio, C., di Sarra, A., and Meloni, D.: Large atmospheric shortwave radiative forcing by Mediterranean aerosol derived 
from simultaneous ground-based and spaceborne observations, and dependence on the aerosol type and single scattering albedo, J. Geophys. Res., 115, D10209, doi:10.1029/2009JD012697, 2010.

Di Biagio, C., Doppler, L., Gaimoz, C., Grand, N., Ancellet, G., Raut, J.-C., Beekmann, M., Borbon, A., Sartelet, K., Attié, J.-L., Ravetta, F., and Formenti, P.: Continental pollution in the western Mediterranean basin: vertical profiles of aerosol and trace gases measured over the sea during TRAQA 2012 and SAFMED 2013, Atmos. Chem. Phys., 15, 9611-9630, doi:10.5194/acp-15-96112015, 2015.

Dubovik, O., Holben, B., Eck, T. F., Smirnov, A., Kaufman, Y. J., King, M. D., Tanré, D., and Slutsker, I.: Variability of absorption and optical properties of key aerosol types observed in worldwide locations, J. Atmos. Sci., 59, 590-608, 2002.

Dubuisson, P., Buriez, J. C., and Fouquart, Y.: High spectral resolution solar radiative transfer in absorbing and scattering media: Application to the satellite simulation, J. Quant. Spectrosc. Ra., 55, 103-126, 1996.

Dubuisson, P., Roger, J., Mallet, M., and Dubovik, O.: A Code to Compute the Direct Solar Radiative Forcing: Application to Anthropogenic Aerosols during the Escompte Experiment, Proc. In- ternational Radiation Symposium (IRS 2004) on Current Problems in Atmospheric Radiation, edited by: Fischer, H., Sohn, B.-J., and Deepak, A., Hampton, 127-130, 23-28 August 2004, Busan, Korea, 2006.

Ebert, M., Weinbruch, S., Rausch, A., Gorzawski, G., Hoffmann, P., Wex, H., and Helas, G.: The complex refractive index of aerosols during LACE 98 as derived from the analysis of individual particles, J. Geophys. Res., 107, 8121, doi:10.1029/2000JD000195, 2002.

Ebert, M., Weinbruch, S., Hoffmann, P., and Ortner, H. M.: The chemical composition and complex refractive index of rural and urban influenced aerosols determined by individual particle analysis, Atmos. Environ., 38, 6531-6545, 2004.

Estellés, V., Martínez-Lozano, J. A., Utrillas, M. P., and Campanelli, M.: Columnar aerosol properties in Valencia (Spain) by ground-based Sun photometry, J. Geophys. Res., 112, D11201, doi:10.1029/2006JD008167, 2007.

Esteve, A. R., Ogren, J. A., Sheridan, P. J., Andrews, E., Holben, B. N., and Utrillas, M. P.: Sources of discrepancy between aerosol optical depth obtained from AERONET and in-situ aircraft profiles, Atmos. Chem. Phys., 12, 2987-3003, doi:10.5194/acp-122987-2012, 2012.

Giorgi, F. and Lionello, P.: Climate change projections for the Mediterranean region. Glob. Planet Change, 63, 90-104, doi:10.1016/j.gloplacha.2007.09.005, 2008.

Gkikas, A., Houssos, E. E., Hatzianastassiou, N., Papadimas C. D., and Bartzokas, A.: Synoptic conditions favouring the occurrence of aerosol episodes over the broader Mediterranean basin, Q. J. Roy. Meteor. Soc., 138, 932-949, 2012.

Hess, M., Koepke, P., and Schult, I.: Optical properties of aerosols and clouds: The software package OPAC, B. Am. Meteorol. Soc., 79, 831-844, 1998.

Horvath, H., Alados Arboledas, L., Olmo, F. J., Jovanovic, O., Gangl, M., Sanchez, C., Sauerzopf, H., and Seidl, S.: Optical characteristics of the aerosol in Spain and Austria and its effect on radiative forcing, J. Geophys. Res., 107, 4386, doi:10.1029/2001JD001472, 2002.
IPCC: Climate Change 2013: The Physical Science Basis. Contribution of Working Group I to the Fifth Assessment Report of the Intergovernmental Panel on Climate Change, edited by: Stocker, T. F., Qin, D., Plattner, G.-K., Tignor, M., Allen, S. K., Boschung, J., Nauels, A., Xia, Y., Bex, V., and Midgley, P. M., Cambridge University Press, Cambridge, United Kingdom and New York, NY, USA, 1535 pp., doi:10.1017/CBO9781107415324, 2013.

Jin, Z., Charlock, T. P., Smith Jr., W. L., and Rutledge, K.: A parametrization of ocean surface albedo, Geophys. Res. Lett., 31, L22301, doi:10.1029/2004GL021180, 2004.

Lelieveld,, J., Berresheim, H., Borrmann, S., Crutzen, P. J., Dentener, F. J., Fischer, H., Feichter, J., Flatau, P. J., Heland, J., Holzinger, R., Korrmann, R., Lawrence, M. G., Levin, Z., Markowicz, K. M., Mihalopoulos, N., Minikin, A., Ramanathan, V., de Reus, M., Roelofs, G. J., Scheeren, H. A., Sciare, J., Schlager, H., Schultz, M., Siegmund, P., Steil, B., Stephanou, E. G., Stier, P., Traub, M., Warneke, C., Williams, J., and Ziereis, H.: Global air pollution crossroads over the Mediterranean, Science, 298, 794-799, 2002.

Liu, Y. and Daum, P.: The effect of refractive index on size distributions and light scattering coefficients derived from optical particle counters, J. Aerosol Sci., 31, 945-957, 2000.

Loeb, N. G. and Su, W.: Direct Aerosol Radiative Forcing Uncertainty Based on a Radiative Perturbation Analysis, J. Climate, 23, 5288-5293, doi:10.1175/2010JCLI3543.1, 2010.

Loeb, N. G. and Su, W. Y.: Direct aerosol radiative forcing uncertainty based on a radiative perturbation analysis, J. Climate, 23, 5288-5293, 2010.

Lyamani, H., Olmo, F. J., Alcántara, A., and Alados-Arboledas, L.: Atmospheric aerosols during the 2003 heat wave in southeastern Spain. I: Spectral optical depth, Atmos. Environ., 40, 6453-6464, 2006.

Lyamani, H., Valenzuela, A., Perez-Ramirez, D., Toledano, C., Granados-Muñoz, M. J., Olmo, F. J., and Alados-Arboledas, L.: Aerosol properties over the western Mediterranean basin: temporal and spatial variability, Atmos. Chem. Phys., 15, 2473-2486, doi:10.5194/acp-15-2473-2015, 2015.

Mallet, M., Roger, J. C., Despiau, S., Dubovik, O., and Putaud, J. P.: Microphysical and optical properties of aerosol particles in urban zone during ESCOMPTE, Atmos. Res., 69, 73-97, 2003.

Mallet, M., Van Dingenen, R., Roger, J. C., Despiau, S., and Cachier, H.: In situ airborne measurements of aerosol optical properties during photochemical pollution events, J. Geophys. Res., 110, D03205, doi:10.1029/2004JD005139, 2005.

Mallet, M., Gomes, L., Solmon, F., Sellegri, K., Pont, V., Roger, J. C., Missamou, T., and Piazzola, J.: Calculation of key optical properties of the main anthropogenic aerosols over the Western French coastal Mediterranean Sea, Atmos. Res., 101, 396-411, 2011.

Mallet, M., Dubovik, O., Nabat, P., Dulac, F., Kahn, R., Sciare, J., Paronis, D., and Léon, J. F.: Absorption properties of Mediterranean aerosols obtained from multi-year ground-based remote sensing observations, Atmos. Chem. Phys., 13, 9195-9210, doi:10.5194/acp-13-9195-2013, 2013.

McComiskey, A., Schwartz, S. E., Schmid, B., Guan, H., Lewis, E. R., Ricchiazzi, P., and Ogren, J. A.: Direct aerosol forcing: Calculation from observables and sensitivities to inputs, J. Geophys. Res., 113, D09202, doi:10.1029/2007JD009170, 2008. 
Meloni, D., di Sarra, A., Pace, G., and Monteleone, F.: Aerosol optical properties at Lampedusa (Central Mediterranean). 2. Determination of single scattering albedo at two wavelengths for different aerosol types, Atmos. Chem. Phys., 6, 715-727, doi:10.5194/acp-6-715-2006, 2006.

Millán, M. M., Mantilla, E., Salvador, R., Carratala, A., Sanz, M. J., Alonso, L., Gangoiti, G., and Navazo, M.: Ozone cycles in the western Mediterranean basin: interpretation of monitoring data in complex terrain, J. Appl. Meteorol., 4, 487-507, 2000.

Müller, D., Ansmann, A., Wagner, F., Franke, K., and Althausen, D.: European pollution outbreaks during ACE 2: Microphysical particle properties and single-scattering albedo inferred from multiwavelength lidar observations, J. Geophys. Res., 107, 4248, doi:10.1029/2001JD001110, 2002.

Nabat, P., Somot, S., Mallet, M., Sevault, F., Chiacchio, M., and Wild, M.: Direct and semi-direct aerosol radiative effect on the Mediterranean climate variability using a coupled Regional Climate System Model, Clim. Dynam., 44, 1127-1155, doi:10.1007/s00382-014-2205-6, 2015.

Nedelec, P., Cammas, J.-P., Thouret, V., Athier, G., Cousin, J.-M., Legrand, C., Abonnel, C., Lecoeur, F., Cayez, G., and Marizy, C.: An improved infrared carbon monoxide analyser for routine measurements aboard commercial Airbus aircraft: technical validation and first scientific results of the MOZAIC III programme, Atmos. Chem. Phys., 3, 1551-1564, doi:10.5194/acp-3-15512003, 2003.

Pace, G., di Sarra, A., Meloni, D., Piacentino, S., and Chamard, P.: Aerosol optical properties at Lampedusa (Central Mediterranean). 1. Influence of transport and identification of different aerosol types, Atmos. Chem. Phys., 6, 697-713, doi:10.5194/acp-6-697-2006, 2006.

Pandolfi, M., Cusack, M., Alastuey, A., and Querol, X.: Variability of aerosol optical properties in the Western Mediterranean Basin, Atmos. Chem. Phys., 11, 8189-8203, doi:10.5194/acp-11-81892011, 2011.

Pandolfi, M., Querol, X., Alastuey, A., Jimenez, J. L., Jorba, O., Day, D., Ortega, A., Cubison, M. J., Comerón, A., Sicard, M., Mohr, C., Prévôt, A. S. H., Minguillón, M. C., Pey, J., Baldasano, J. M., Burkhart, J. F., Seco, R., Peñuelas, J., van Drooge, B. L., Artiñano, B., Di Marco, C., Nemitz, E., Schallhart, S., Metzger, A., Hansel, A., Lorente, J., Ng, S., Jayne, J., and Szidat, S.: Effects of sources and meteorology on particulate matter in the Western Mediterranean Basin: An overview of the DAURE campaign, J. Geophys. Res.-Atmos., 119, 4978-5010, doi:10.1002/2013JD021079, 2014.

Pérez, N., Pey, J., Castillo, S., Viana, M., Alastuey, A., and Querol, $\mathrm{X}$.: Interpretation of the variability of levels of regional background aerosols in the Western Mediterranean, Sci. Total Environ., 407, 527-540, 2008.

Pey, J., Querol, X., and Alastuey, A.: Discriminating the regional and urban contributions in the North-Western Mediterranean: PM levels and composition, Atmos. Environ., 44, 1587-1596, 2010.
Piazzola, J., Sellegri, K., Bourcier, L., Mallet, M., Tedeschi, G., and Missamou, T.: Physicochemical characteristics of aerosols measured in the spring time in the Mediterranean coastal zone, Atmos. Environ., 54, 545-556, 2012.

Ramana, M. V. and Ramanathan, V.: Abrupt transition from natural to anthropogenic aerosol radiative forcing: Observation at the ABCMaldives Climate Observatory, J. Geophys. Res., 111, D20207, doi:10.1029/2006JD007063, 2006.

Raut, J.-C. and Chazette, P.: Vertical profiles of urban aerosol complex refractive index in the frame of ESQUIF airborne measurements, Atmos. Chem. Phys., 8, 901-919, doi:10.5194/acp-8-9012008, 2008.

Russell, P. B., Bergstrom, R. W., Shinozuka, Y., Clarke, A. D., DeCarlo, P. F., Jimenez, J. L., Livingston, J. M., Redemann, J., Dubovik, O., and Strawa, A.: Absorption Angstrom Exponent in AERONET and related data as an indicator of aerosol composition, Atmos. Chem. Phys., 10, 1155-1169, doi:10.5194/acp-101155-2010, 2010.

Saha, A., Mallet, M., Roger, J. C., Dubuisson, P., Piazzola, J., and Despiau, S.: One year measurements of aerosol optical properties over an urban coastal site: Effect on local direct radiative forcing, Atmos. Res., 90, 195-202, 2008.

Stamnes, K., Tsay, S. C., Wiscombe, W., and Jayaweera, K.: Numerically stable algorithm for discrete-ordinate-method radiative transfer in multiple scattering and emitting layered media, Appl. Optics, 27, 2502-2509, 1988.

Stier, P., Schutgens, N. A. J., Bellouin, N., Bian, H., Boucher, O., Chin, M., Ghan, S., Huneeus, N., Kinne, S., Lin, G., Ma, X., Myhre, G., Penner, J. E., Randles, C. A., Samset, B., Schulz, M., Takemura, T., Yu, F., Yu, H., and Zhou, C.: Host model uncertainties in aerosol radiative forcing estimates: results from the AeroCom Prescribed intercomparison study, Atmos. Chem. Phys., 13, 3245-3270, doi:10.5194/acp-13-3245-2013, 2013.

Stohl, A., Hittenberger, M., and Wotawa, G.: Validation of the Lagrangian particle dispersion model Flexpart against large-scale tracer experiment data, Atmos. Environ., 32, 4245-4264, 1998.

Toledano, C., Cachorro, V. E., Berjon, A., de Frutos, A. M., Sorribas, M., de la Morena, B. A., and Goloub, P.: Aerosol optical depth and Ångstrom exponent climatology at El Arenosillo AERONET site (Huelva, Spain), Q. J. Roy. Meteor. Soc., 133, 795-807, doi:10.1002/qj.54, 2007.

Weingartner, E., Saathof, H., Schnaiter, M., Streit, N., Bitnar, B., and Baltensperger, U.: Absorption of light by soot particles: Determination of the absorption coefficient by means of Aethalometers, J. Aerosol Sci., 34, 1445-1463, 2003. 